\title{
Financial Development and the Sources of Growth and Convergence
}

\author{
Oleg Badunenko* and Diego Romero-Ávila ${ }^{\dagger}$
}

15 December 2011

\begin{abstract}
We extend the production frontier framework employed by Kumar and Russell (2002) and Henderson and Russell (2005) by incorporating financial development. Our analysis convincingly shows that (1) failure to account for financial development overstates the role of physical capital accumulation in labor productivity growth, (2) most of this overstated contribution stems from the efficiency-enhancing role of well-functioning financial institutions, (3) international polarization is solely driven by efficiency changes (catching-up), and (4) increased distributional dispersion of productivity is primarily driven by technological change. Model's extensions to account for the growth effect of changes in the institutional environment only add to the argument about the overstated role of physical capital and reinforce the importance of financial development in explaining growth.
\end{abstract}

JEL: O47, D24, G21

Keywords: Financial Development, Financial Efficiency, Productivity Growth, Technological Change, Production Frontier, Convergence, Institutions

${ }^{*}$ University of Cologne, Cologne Graduate School in Management, Economics and Social Sciences, Richard-Strauss-Str. 2, 50931, Cologne, Germany. Phone: +49.221.470.1285. Fax: +49.221.470.1229, E-mail: obadunen@uni-koeln.de.

${ }^{\dagger}$ Pablo de Olavide University, Department of Economics, Carretera de Utrera, Km. 1, Sevilla, 41013, Tel.: +34954348381, Fax: +34954349339, Spain, E-mail: dromtor@upo.es. 


\section{Introduction}

Early authors, dating as far back as Bahegot (1973), von Bohm-Bawerk (1891) and Schumpeter (1912), emphasized the pivotal role of financial institutions in the process of economic development, particularly in improving the efficiency of capital allocation. Goldsmith (1969) argues that the financial superstructure accelerates economic growth by facilitating the migration of funds to the best user.

However, only the most recent vintage of endogenous growth models along the tradition of Romer (1986), Lucas (1988) and Romer (1990) provided the analytical foundations to modeling the influence of financial development on growth through the efficiency with which capital is allocated across different investment alternatives. This influence is exerted through the following mechanisms: collecting and analysis of information about capital allocation alternatives including production technologies and entrepreneurial innovative activities (Greenwood and Jovanovic (1990), King and Levine (1993a), Galetovic (1996) and Greenwood et al. (2010a)); pooling of funds and facilitating risk management and diversification leading to enhanced assets liquidity (Bencivenga and Smith (1991), Levine (1991), Saint-Paul (1992), Obstfeld (1994), Devereux and Smith (1994) and Acemoglu and Zilibotti (1997)); and amelioration of liquidity risk through reduced trading costs (Bencivenga et al. (1995)).

More recently, a line of research using calibration methods has investigated the role of financial frictions in explaining productivity differences across countries. Buera et al. (2011) calibrate a model of entrepreneurship where financial frictions distort the allocation of capital and talent across production units. The assumption that manufacturing is characterized by a larger scale than services makes the former more vulnerable to financial frictions. In equilibrium, they find a small number of entrepreneurs and too large establishments in manufacturing, while the opposite occurs in services. This appears to be supported by establishment-level data for Mexico and the U.S. Moll (2010) develops a model where entrepreneurs are subject to borrowing constraints and idiosyncratic productivity shocks and can self-finance their investment. Productivity for being an active entrepreneur is assumed to depend on the quality of credit markets. He finds that self-financing can undo misallocation of capital caused by financial frictions only if productivity shocks are sufficiently correlated over time. This renders no effect on aggregate productivity. Disciplining the model with plant-level data for Chile and Colombia, Moll (2010) finds that financial distortions can account for aggregate productivity losses of up to $25 \%$ relative to the U.S. Along similar lines, Greenwood et al. (2010b) develop a dynamic costly state verification model of financial intermediation which is calibrated to match the intermediation spreads and the firm-size distribution of the U.S. economy. Their evidence indicates that improvements in financial intermediation can explain $30 \%$ 
of U.S. growth and that the reallocation of funds by adopting the best world financial practice would raise output by 36 to $45 \%$. In addition, Amaral and Quintin (2010) quantify the impact of differences in the amount of financial intermediation due to limited enforcement of financial contracts. In their model, poor contract enforcement leads to less capital used in production as well as to capital not being channeled to the most productive use, thus reducing output. Their model can explain a maximum threefold difference in income between the U.S. and middle-income countries.

Finally, Midrigan and Xu (2010) elaborate a model of establishment dynamics with financial frictions in the form of borrowing constraints, which is then carefully parameterized to match manufacturing plant-level data facts for Korea and Colombia. In doing so, they pay particular attention to the dispersion in output growth across establishments as well as to the dispersion in rates of return to capital across young and old plants. In their version of the model with no entry or exit into entrepreneurship, the key parameter determining the link between financial intermediation and total factor productivity (TFP) is the standard deviation of shocks to an entrepreneur's productivity. Thus, a larger shock implies a higher need for external funds and higher losses in the event of financing constraints. Little time-series variability in the plant-level output data analyzed points to the relatively low importance of productivity losses due to financial distortions. Central to this finding is that entrepreneurs quickly accumulate funds to undo the capital misallocation caused by borrowing constraints. ${ }^{1}$

Despite this theoretical effort, not much has been done at the cross-country level to model empirically the efficiency-augmenting effect of financial development on capital allocation, and in turn its impact on economic growth. King and Levine (1993b), Neusser and Kugler (1998), Beck, Levine and Loayza (2000) and Levine and Zervos (1998) constitute some exceptions. Their evidence shows that the financial sector raises output via improved allocative efficiency, which is captured in their growth accounting framework as a residual -as given by TFP growth. ${ }^{2}$

In this paper, we propose a novel approach to modelling the efficiency effect of the financial sector in allocating resources to the most productive use -as a possible engine of growth- that circumvents the need to measure capital allocative efficiency as a residual. For that purpose, we regress the variables agreed in the literature to best measure

1 Small TFP losses from misallocation (that are no larger than 7\%) are again found when the model is extended to allow for occupational choice.

2 The novel case-study of Jayaratne and Strahan (1996) for U.S. intrastate branch deregulation also rendered positive growth effects from finance through improved allocative efficiency. See also the industry-level studies of Wurgler (2000) and Fisman and Love (2004) for specific mechanisms pointing to a more efficient intersectoral capital allocation across countries. Using an alternative experiment, Rajan and Zingales (1998) provided evidence that industries that are relatively more in need of external finance exhibit faster growth in countries with more developed financial systems. Levine (1997) and Levine (2005) provide authoritative reviews of the theories and empirics behind the finance and growth nexus. 
financial intermediation efficiency on proxies for financial development. The coefficients obtained serve as the basis for the construction of the financial efficiency augmentation factors. These factors are used to multiplicatively augment physical capital, which is measured in efficiency units. ${ }^{3}$ The intuition behind this way of modelling is that one unit of physical capital is expected to be more efficient in a country where financial intermediaries perform the function of allocating funds from savers to investors more efficiently. We then incorporate these financial efficiency augmentation factors into the production frontier approach previously employed by Kumar and Russell (2002, henceforth KR) and Henderson and Russell (2005, HR hereafter). ${ }^{4}$ This modelling strategy will allow us to provide conceptually theoretical foundations within a production frontier framework of the impact of financial development on labor productivity growth. ${ }^{5}$ Despite this augmentation, a further advantage is that we can still view the system on two dimensions by working with output and efficiency units of physical capital per efficiency units of labor.

The objective of this article is to develop a nexus between three important literatures:

1) the deterministic frontier production function literature based on the pioneering work of Farrell (1957), 2) the work on the sources of cross-country labor productivity growth and international macroeconomic convergence, and 3) the finance and growth literature. Hence, to the best of our knowledge, this is the first study that explicitly incorporates financial development into a production frontier approach. The advantage of using this

3 Consider a simple production function that, for simplicity, depends only on the stock of physical capital $k_{t}: y_{t}=f\left(k_{t}\right)$, where $k_{t}$ and $y_{t}$ denote output and the capital stock at time $t$. By totally differentiating it we obtain: $\widehat{y}=\frac{d k_{t}}{y_{t}} \frac{d y_{t}}{d k_{t}}=\frac{d k_{t}}{y_{t}} f \prime\left(k_{t}\right)$, where $\widehat{y}$ denotes the growth rate of output, $\frac{d k_{t}}{y_{t}}$ is the savings rate and $f \prime\left(k_{t}\right)$ is the marginal productivity of capital. To the extent that financial development can either raise the savings rate or the marginal productivity of capital, the above expression captures the two transmission channels through which financial development may affect growth (see more details in de Gregorio and Guidotti (1995)). This also illustrates, as in our modeling strategy, how the accumulation of physical capital interacts with the productivity (efficiency) with which capital is allocated across investment alternatives to render higher growth. As noted above, endogenous growth models incorporating the role of financial factors appear to raise growth mainly via the improved allocative efficiency of investment through a variety of mechanisms such as overcoming problems of moral hazard and adverse selection, which will facilitate the channeling of funds to the most productive use, thereby reducing the firm's cost of raising money from outsiders (Rajan and Zingales (1998)).

4 Employing deterministic nonparametric frontier methods, KR decompose productivity growth into components attributable to technological change (shifts in the world production frontier), technological catch-up due to efficiency changes (movements toward or away from the frontier) and physical capital accumulation (movements along the frontier). Their results indicate that both productivity growth and international polarization are driven primarily by capital deepening (i.e. changes in the physical capital to labor ratio) in a wide sample of 57 countries over the period 1965-1990. These results clearly change when HR incorporates human capital as an augmenting factor of raw labor. Besides confirming the KR finding of non-neutral technological change, the other findings appear substantially modified: 1) about one-third of the productivity change attributed by KR to physical capital deepening should, instead, be assigned to human capital accumulation, 2) labor productivity growth is driven predominantly by physical and human capital, 3) international polarization is caused primarily by technological catchingup via efficiency changes, with help from physical and/or human capital accumulation, and 4) increased productivity dispersion is mainly driven by physical capital accumulation.

5 Throughout the text, we will interchangeably use labor productivity and productivity. 
(deterministic) nonparametric production frontier approach -over previous regressionbased studies that are heavily model-driven- is that is a purely data-driven method, which does not require specification of any particular production function technology (e.g. Cobb-Douglas or CES), nor it does not require the existence of perfectly competitive markets or Hicks-neutral technological change. Unlike standard growth accounting, this framework allows us to distinguish between catching-up (movements towards the frontier) and technological change (shifts in the frontier).

Inspired by KR and HR, we employ nonparametric production-frontier methods to theoretically derive a quinquepartite decomposition of labor productivity growth into the components attributable to technological change, technological catch-up, capital deepening, human capital accumulation and financial development. In addition, we examine the evolution and transformation of the worldwide labor productivity distribution from unimodality to bimodality, which is well-known as twin-peaks convergence (see Quah (1996a,b, 1997)). The analysis is conducted for a sample of 57 countries for which full data are available between 1965 and 2005 .

Our results confirm the KR's and HR's finding that technological change was nonneutral, however, we challenge other HR's empirical findings. In particular, we find that a substantial part of the productivity growth attributable by HR to physical capital accumulation should, instead, be attributed to the allocative efficiency-enhancing role of financial development. On average, the contribution of physical capital accumulation substantially falls from 71 to $52 \%$. This reduction is almost matched by the productivity contribution of financial development, which equals $15 \%$. The contributions from human capital accumulation and technological progress slightly increase from 21.5 to $26 \%$, and from 11.5 to $13 \%$, respectively. In addition, the augmentation of physical capital with estimates capturing the allocative efficiency-augmenting role of financial intermediaries uncovers higher inefficiency, i.e. higher distance from the best-practice frontier. Our findings also indicate that polarization is solely driven by efficiency changes implying movements toward or away from the frontier. Finally, the increased dispersion exhibited by the productivity distribution from 1965 to 2005 is accounted for primarily by technological change, accompanied by financial development and/or physical and human capital accumulation. The main results appear to be fairly robust to (1) the use of alternative sets of financial efficiency augmentation factors, (2) restricting the sample period to that analyzed by HR: 1965-1990, and (3) the incorporation of institutional variables complementary to financial development, which results in a sexapartite decomposition of labor productivity change.

The rest of the paper is organized as follows. Section II describes the data and construction of the financial efficiency factors with which physical capital is augmented. Section III constructs the worldwide technology frontiers in 1965 and 2005, thereby pro- 
viding the efficiency scores, i.e. the distances from the frontier, for each of the 57 countries considered. Section IV provides the results from the quinquepartite decomposition of productivity growth into its components. Section V examines the components driving the mean-preserving shifts in the world productivity distribution. Section VI provides some sensitivity analyses and Section VII concludes.

\section{Data}

The data used for output, physical capital and labor are derived from the PWT version 7.0 (Heston et al. (2011)). The number of workers is obtained as RGDPCH * POP/RGDPWOK, where RGDPWOK is real GDP per worker. The measure of output is calculated as RGDPWOK multiplied by the number of workers; the resulting output is in 2005 international dollars. Real aggregate investment in international dollars is computed as RGDPL * POP * KI, where RGDPL is the real GDP computed via the Laspeyres index and KI is the investment share of real GDP.

The major difference between the measurements of capital stock in HR using the PWT version 5.6 versus PWT version 7.0 lies in the disaggregation of investment. In version 5.6, the investment series is disaggregated into five components: machinery, transportation equipment, residential construction, business construction, and other construction. Different depreciation rates (see Hulten and Wykoff (1996)) are then employed in the perpetual inventory method. Here we do not have this level of disaggregation and are forced to use a common depreciation rate, 0.06 . Following standard practice, we compute the initial capital stock, $K_{0}$, as $I_{0} /(g+\delta)$, where $I_{0}$ is the value of the investment series in the first year it is available, and $g$ is the average geometric growth rate for the investment series between the first year with available data and 1970 (see Caselli and Feyrer (2007)).

For human capital, we also update HR's data and employ the Barro and Lee (2010)'s average years of schooling of population over 15. Employing consistent census data from UNESCO, Barro and Lee (2010) improve the accuracy of the level of education, which is dissaggregated by gender and age groups. In addition, they relax the assumption of uniform mortality rates across all age groups, which caused a downward bias in previous estimates of educational attainment. Instead, they use new estimates of mortality rates and completion rates dissaggregated by age and educational levels.

As in HR, in constructing the stock of human capital we adopt the Hall and Jones (1999) procedure and the Psacharopoulos (1994) survey of wage equations evaluating the returns to education to transform average years of schooling data into a human capital index. Letting $\epsilon_{j t}$ represent the average number of years of education of the adult population in country $j$ at time $t$ and define labor in efficiency units in country $j$ at time $t$ 
by

$$
\widehat{L}_{j t}=H_{j t} L_{j t}=h\left(\epsilon_{j t}\right) L_{j t}=e^{\phi\left(\epsilon_{j t}\right)} L_{j t}
$$

where $\phi$ is a piecewise linear function, with a zero intercept and a slope of 0.134 through the fourth year of education, 0.101 for the next four years, and 0.068 for education beyond the eighth year. From expression 1, the rate of return to education (where $\phi$ is differentiable) can be easily obtained as follows:

$$
\frac{\partial \ln h\left(\epsilon_{j t}\right)}{\partial \epsilon_{j t}}=\phi^{\prime}\left(\epsilon_{j t}\right)
$$

and $h(0)=1 .^{6}$

\subsection{Tracing the Link between Financial Intermediary Develop- ment and Financial Efficiency}

Theory focuses on the role of financial institutions in channeling funds from savers to investors, gathering information and allocating capital to the highest-yield investment projects, exerting corporate control, pooling funds, managing risks and facilitating the exchange of goods and services, and how these affect a better allocation of resources and economic growth. Ideally, our measures of financial development should reflect these functions provided by the financial system with the aim of enhancing the efficiency with which capital is allocated. However, there is little consensus on how to properly measure them, and even more so for our wide sample of countries. What the extant literature has done so far is to use some crude proxies which, as noted by Rajan and Zingales (1998), may miss many of the aspects thought to be pivotal to a modern financial system. ${ }^{7}$

Among all the financial development proxies employed in cross-country studies assessing the finance and growth relationship, our preferred measure is private credit by deposit money banks and other non-bank financial institutions over GDP -which we denote by CREDIT1. Unlike other measures like gross claims on the non-financial private sector as a percentage of GDP (PRIVY), this proxy excludes credits issued by the central and de-

6 The values of the augmentation factors $\left(H_{j t}=e^{\phi\left(\epsilon_{j t}\right)}\right)$ for 1965 and 2005 are provided in an unpublished appendix, which is available in the authors' homepages.

7 In regression-based studies, the direction of causality in the finance and growth nexus is another thorny issue that has not yet been completely settled. For instance, King and Levine (1993b) find evidence that the level of credit in 1960 is a good predictor of subsequent growth over the next 30 years. However, as noted by Rajan and Zingales (1998), the financial sector may increase lending in anticipation of better future growth opportunities. This would imply that financial development may be acting as a leading indicator rather than as a causal factor. Arguably, this causation issue may be less of a problem within this nonparametric production frontier approach as the conceptual quinquepartite decomposition used to examine growth is directly derived from a production function, rather than from growth of labor productivity. 
velopment banks. ${ }^{8}$ In addition, CREDIT1 is more comprehensive than the ratio of private credit by deposit money banks over GDP (CREDIT2), which excludes the credit granted by non-deposit money banks to the private sector. Not only CREDIT1 but also CREDIT2 and PRIVY exclude credit granted to the public sector and government agencies, which are thought to be less efficient in using the funds borrowed. One traditional measure employed as early as in Goldsmith (1969) and McKinnon (1973) is the ratio of liquid liabilities to GDP (LLY), which entails "currency held outside the banking system plus demand and interest-bearing liabilities of banks and non-bank financial intermediaries".

Since one of the main functions of financial intermediaries is to channel funds from savers to investors, we take a significant step forward in the extant literature by trying to trace the link between these crude proxies for financial development and the efficiency with which this function is performed. Towards this end, we regress two measures of the efficiency with which commercial banks allocate funds from depositors to the best investment alternatives on our four financial development proxies (CREDIT1, CREDIT2, PRIVY and LLY). ${ }^{9}$ The first indicator, net interest margin, is the accounting value of a bank's net interest revenue as a share of its total earning assets. The second indicator, overhead costs, equals the accounting value of a bank's overhead costs as a share of its total assets. ${ }^{10}$ Both measures are constructed by Beck et al. (2010) as unweighted averages across all banks in a country for a given year and the source of the individual banks' balance sheets data is Fitch IBCA's Bankscope Database and other individual country sources. The time coverage for these financial efficiency measures is $1987-2005 .{ }^{11}$

\footnotetext{
8 As noted by King and Levine (1993b), PRIVY may be problematic since it may indirectly capture the extent of public sector borrowing from the central bank rather than the type of financial services stressed above.

9 As explained in the Financial Structure Database (see Beck, Demirgüç-Kunt and Levine (2000) and Beck et al. (2010)), which is our main source for the financial development data, end-of-year financial balance sheet variables are deflated by the end of year consumer price index (CPI) and GDP series by the annual CPI. This is because financial balance sheet items are measured at the end of the year, while GDP flows are measured over the year. The average of the real financial variable in years $t$ and $t-1$ is computed, which is then divided by real GDP measured in year $t$.

${ }^{10}$ As noted by Beck et al. (2010), higher levels of net interest margins and overhead costs imply lower levels of intermediation efficiency, as given by the higher wedge between lending and deposit interest rates. In addition, Greenwood et al. (2010a) and Greenwood et al. (2010b) emphasize the fact that increases in the efficiency of financial intermediation due to improved information production will be translated into lower costs of intermediation (i.e. lower spread between the internal rate of return accruing to the investor and the return on savings received by savers). Thus, we can argue that net interest margin and overhead costs may be good proxies for these costs of intermediation, which include ex-ante screening and ex-post monitoring of projects, the costs of misappropriation of funds by management and related financial frictions.

${ }^{11}$ Using data from the small and medium-size firm lending division of a large multinational bank that operates in 15 emerging economies, Liberti and Mian (2010) estimate a country's collateral spread as the difference in collateralization rates between high and low-risk loans. They find evidence that improvements in the level of financial development leads to a substantial reduction in the collateral spread. Arguably, collateral spread would constitute an attractive measure of financial intermediation efficiency, but lack of data on a cross-country basis prevents us from using it as a complement to net interest margin and overhead costs.
} 
For the construction of the financial efficiency augmentation factors that interact physical capital, we employ a piecewise linear function with a varying slope for different financial development regimes, which translates into the following specification:

$$
\ln (\text { Financial Efficiency })_{j}=\alpha+\beta_{0} F D_{j}+\beta_{1} F D_{j} \times L R_{j}+\beta_{2} F D_{j} \times H R_{j}+X_{j}+\varepsilon_{j}
$$

where Financial Efficiency is measured as the inverse of either net interest margin or overhead costs averaged over the period 1987-2005, FD represents any of our four crude proxies for financial development averaged over the period 1965-2005, and $X$ stands for a set of control variables that includes the log of initial GDP per capita (ly65) and the government ownership share of banks in 1970 (GB70). ${ }^{12}$ In order to allow for the different effect of financial development levels on financial intermediation efficiency, we define three regions of financial development: low, middle and high. ${ }^{13}$ This is captured in specification 3 through low region (LR) and high region (HR) dummy variables such that LR equals 1 if FD is below a certain lower threshold and zero otherwise. Likewise, HR equals 1 if FD is above a certain upper threshold and zero otherwise. Once these dummy variables interact with the variable FD, the effect of financial development on financial efficiency in the low, middle and high regions are $\beta_{0}+\beta_{1}, \beta_{0}$, and $\beta_{0}+\beta_{2}$, respectively. Since these thresholds are unknown a priori, we place the lower and upper thresholds at the 25 th and 75 th percentiles of the distribution of each financial development measure. ${ }^{14}$

\footnotetext{
12 This variable stems from La Porta et al. (2002) and is defined as the share of the assets of the top ten banks in a given country owned by the government in 1970. According to political theories, ownership of banks by governments enables them to fund inefficient but politically attractive projects, with the negative repercussions that may bring on financial efficiency. In addition, to allow for the possibility that cross-country differences in income are not driving the financial development and financial efficiency nexus, the log of initial GDP per capita is included. A further reason for doing so is that growth theory modeling the effect of finance assumes the existence of fixed costs for credit markets to be operational, which can be only afforded when the economy reaches a minimum size.

13 There are some theoretical justifications for allowing for a varying effect of financial development levels on the efficiency with which savings are allocated to those projects with the highest returns. For instance, Acemoglu and Zilibotti (1997) emphasize the importance of economies of scale in this process since high-return projects tend to be indivisible and require a minimum size. Bencivenga and Smith (1991) and Saint-Paul (1992) propose theoretical models in which the shift from highly liquid but low-productive assets to less liquid but highly productive ones is facilitated by the scale of liquidity risk elimination. In models such as Greenwood and Jovanovic (1990) where financial intermediaries emerge to perform the task of gathering information about the best investment alternatives, a minimum financial sector size makes this process less costly. Besides information costs, Bencivenga et al. (1995) stress the role of trading costs in raising market liquidity. In this setting, long-gestation projects, though enjoying higher returns, require the transfer of ownership throughout their duration. Liquidity levels above a certain threshold reduce the cost of exchanging ownership, thus inducing a shift to long-gestation, high-yield, technologies.

14 A similar strategy has been followed by Rioja and Valev (2004) for the analysis of the effect of different regimes of financial development on economic growth. Their results point to the highest positive effect in the middle region compared to the high region, while an uncertain effect for the low region. Their results hold remarkably well when they vary the location of the low and high thresholds.
} 
Table 1 presents the estimation results of three models for each of the financial efficiency measures, where the financial development proxy taken as dependent variable is CREDIT1. ${ }^{15}$ We report the sum of coefficients for the three regions and the p-values associated with the null hypothesis of non-significance of the sum of coefficients when appropriate. Model 1 only controls for CREDIT1 and an intercept. The evidence points to a significantly positive effect of financial development on financial efficiency for the middle and high regions at the $1 \%$ significance level, while the effect for the low region is also positive but insignificant at the $90 \%$-confidence level. Interestingly, the positive effect in the middle region is larger than in the high region, and the F-statistic points to the joint significance of the coefficients on CREDIT1 for the three regions. This gives support to the use of a piecewise linear function with a different slope for each of the financial development regimes, when constructing the financial efficiency factors with which physical capital is augmented. In addition, the variability in financial efficiency that is explained with CREDIT1 equals 45\%. As can be observed in Table 1, these results are robust to the inclusion of initial GDP and GB70 as additional controls as well as to the use of overhead costs as an alternative measure of financial efficiency. ${ }^{16}$

\section{[Insert Table 1 about here]}

Once we have estimated the coefficients capturing the positive effect of financial development on the efficiency with which commercial banks channel funds from savers to investors, we are in a position to define physical capital in efficiency units in country $j$ at time $t$ by:

$$
\hat{K}_{j t}=F_{j t} K_{j t}=f\left(\mathrm{FD}_{j t}\right) K_{j t}=e^{\psi\left(\mathrm{FD}_{j t}\right)} K_{j t}
$$

where $\psi$ is a piecewise linear function that depends on the estimated effect of financial development levels on financial efficiency, with a zero intercept and slope coefficients obtained from the estimation of specification 3. Arguably, we can measure the return to financial development in terms of financial efficiency as:

$$
\frac{\partial \ln f\left(\mathrm{FD}_{j t}\right)}{\partial \mathrm{FD}_{j t}}=\psi^{\prime}\left(\mathrm{FD}_{j t}\right),
$$

where $f(0)=1$, which would indicate that in a country with no financial development, physical capital is not augmented.

15 Similar results follow for the three other financial development proxies. To save space these results are not reported, but are provided in the unpublished appendix.

16 The results remain also robust to moving the lower and upper thresholds to the left and right of our preferred threshold choice, i.e. 20th/80th and 30th/70th percentiles, respectively. These unreported results are available in the unpublished appendix. 
Table 2 lists the 57 countries included in the analysis along with the values of the financial efficiency augmentation factors for 1965 and 2005 derived from model 3, with net interest margin used as the financial efficiency measure. ${ }^{17}$ Remarkably, the financial efficiency augmentation factor appears to increase over this 40-year period in most of the countries, with the exceptions of Cote d'Ivoire, Italy, Mexico, Norway, Sierra Leone and Syria, where financial efficiency has slightly fallen.

\section{[Insert Table 2 about here]}

In addition, Figure 1 depicts the distributions of the financial efficiency augmentation factors in 1965 and 2005. ${ }^{18}$ Besides exhibiting an increase in the mean level of financial efficiency, Figure 1 shows that there has been a substantial increase in dispersion in the distribution over the 40-year period considered. While the 1965 distribution exhibits a large probability mass concentration around relatively low values, the 2005 distribution spreads over a much larger range of values. This entails that many countries have seen their levels of financial efficiency substantially increased. In fact, a formal statistic testing for the equality of both distributions (which will be explained below) rejects the null hypothesis of distributional equality at the $1 \%$ level $(p$-value $=0.000)$.

[Insert Figure 1 about here]

\section{Construction of the Technology Frontier and Effi- ciency Scores}

\subsection{Data Envelopment Analysis}

We construct the world production-frontier ${ }^{19}$ and the associated efficiency levels of individual economies (distances from the frontier) nonparametrically. ${ }^{20}$ The basic idea is to envelop the data in the smallest convex cone, where the upper boundary of this set represents the "best practice" production-frontier. One of the major benefits of this approach

\footnotetext{
17 Though focusing in the main body of the paper on the evidence obtained with this particular set of augmentation factors, we will check the sensitivity of all our results to the use of alternative financial efficiency augmentation factors obtained from the different combinations between our two financial efficiency measures and four financial development proxies. In addition, fairly similar results would follow throughout the empirical analysis if we built the financial efficiency augmentation factors from models like 1 and 2 in Table 1.

18 Throughout the text, the distributions are nonparametric kernel-based density estimates.

${ }^{19}$ For expositional purposes, we refer to the world production frontier even if we are analyzing only a subsample consisting of 57 countries for which full data were available. To the extent that industrialized countries are likely to construct the true world frontier, this distinction becomes less important. In fact, as reported below, the three frontier economies in 2005 (Belgium, Norway and Singapore) are all well developed.

20 The reader is referred to Färe et al. (1985) for details on Data Envelopment Analysis.
} 
is that it does not require prior specification of the functional form of the technology. It is a data-driven approach, implemented with standard mathematical programming algorithms, which allows the data to tell the form of the production function.

Our technology contains five macroeconomic variables: aggregate output and four aggregate inputs - labor, physical and human capital, and financial development. ${ }^{21}$ Let $\left\langle Y_{i t}, K_{i t}, L_{i t}, H_{i t}, F_{i t}\right\rangle, t=1,2, \ldots, T, i=1,2, \ldots, N$, represent $T$ observations on these five variables for each of the $N$ countries. We adopt a standard approach in the macroeconomic literature and assume that human capital enters the technology as a multiplicative augmentation of physical labor input. Furthermore, as motivated above, we consider financial development to multiplicatively augment physical capital so that our NT observations are $\left\langle Y_{i t}, \hat{K}_{i t}, \hat{L}_{i t}\right\rangle, t=1,2, \ldots, T, i=1,2, \ldots, N$, where $\hat{L}_{i t}=L_{i t} H_{i t}$ and $\hat{K}_{i t}=K_{i t} F_{i t}$ are the amounts of labor and capital input measured in efficiency units in country $i$ at time $t$. The constant returns to scale technology for the world in period $t$ is constructed by using all the data up to that point in time as

$$
\mathcal{T}_{t}=\left\{\begin{array}{r}
\langle Y, \hat{L}, \hat{K}\rangle \in \Re_{+}^{3} \mid Y \leq \sum_{\tau \leq t} \sum_{i} z_{i \tau} Y_{i \tau}, \\
\hat{L} \geq \sum_{\tau \leq t} \sum_{i} z_{i \tau} \hat{L}_{i \tau}, \\
\hat{K} \geq \sum_{\tau \leq t} \sum_{i} z_{i \tau} \hat{K}_{i \tau}, \\
z_{i \tau} \geq 0 \forall i, \tau
\end{array}\right\},
$$

where $z_{i \tau}$ are the activity levels. By using all the previous years data, we preclude implosion of the frontier over time. It is difficult to believe that the world technological frontier could implode or that the stock of knowledge decays. Thus, following an approach first suggested by Diewert (1980), we chose to adopt a construction of the technology that precludes such technological degradation.

The Farrell (1957) (output-based) efficiency index for country $i$ at time $t$ is defined by

$$
E\left(Y_{i t}, \hat{L}_{i t}, \hat{K}_{i t}\right)=\min \left\{\lambda \mid\left\langle Y_{i t} / \lambda, \hat{L}_{i t}, \hat{K}_{i t}\right\rangle \in \mathcal{T}_{t}\right\}
$$

This index is the inverse of the maximal proportional amount that output $Y_{i t}$ can be expanded while remaining technologically feasible, given the technology and input quantities. It is less than or equal to unity and takes the value of unity if and only if the it observation is on the period-t production-frontier. In our special case of a scalar output, the output-based efficiency index is simply the ratio of actual to potential output evaluated at the actual input quantities.

\footnotetext{
21 To easy exposition, financial development refers to the allocative efficiency-enhancing role of financial intermediaries when channelling resources from savers to the best investment projects, as captured by our financial efficiency augmentation factors.
} 


\subsection{Efficiency Scores and Technological Catching-up}

Table 3 reports the efficiency scores of each of the 57 countries for 1965 and 2005. The scores are presented for two cases where capital stock is measured in efficiency units (i.e. augmented by financial development), and where it is not. Remarkably, even though the mean efficiency score in 1965 slightly falls from 0.70 to 0.69 due to the incorporation of the allocative efficiency effect of financial development, there is some unmasked heterogeneity across countries. For 28 countries the efficiency index increases, whereas for 18 countries it decreases and remains unaltered for the rest. We also point out the fact that incorporating financial development makes Canada and France move to the 1965 frontier, while Costa Rica and the U.S. are no longer on the 1965 frontier. Irrespective of the inclusion of financial development, Nepal, the Netherlands, Sierra Leone, Syria and the U.K. remain situated on the 1965 frontier. ${ }^{22}$

In addition, the mean efficiency score in 2005 appears to fall from 0.64 to 0.60 when we include financial development. This suggests that the augmentation of physical capital with an estimate for the efficiency-enhancing role of financial intermediaries in allocating resources increases, on average, the distance from the best-practice frontier. By incorporating financial development into the analysis, Belgium and Norway replace the U.K. as 2005 frontier economies, while Singapore remains on the frontier. As with mean efficiency, the same pattern of increasing inefficiency in 2005 due to the incorporation of financial development appears in most of the countries (34 in total). In addition, we find higher efficiency levels for 18 countries while unchanged efficiency scores for the remaining economies.

\section{[Insert Table 3 about here]}

Figure 2 plots the distributions of the efficiency index in 1965 and 2005. Besides showing a fall in mean efficiency between 1965 and 2005, this Figure depicts the existence of a substantial shift of probability mass away from near the frontier towards the lower end of the distribution. Indeed, visual inspection of the 2005 efficiency distribution gives some evidence of bimodality, with the lower mode being slightly greater than the higher mode. This further reflects the widespread tendency for economies to move away from the frontier due to efficiency losses over this 40-year period, irrespective of their level of development. It will thus be interesting to analyze below whether polarization in efficiency levels drives the possible emergence of bimodality in the distribution of labor productivity.

\section{[Insert Figure 2 about here]}

\footnotetext{
$\overline{22}$ As noted by KR, a country like Sierra Leone characterized by a very small factor endowment can be on the frontier to the extent that it makes an efficient use of its meager factor endowment. So it is the lack of factors rather than efficiency losses the reason why this country is so poor.
} 
Moreover, the assumptions of constant returns to scale along with the labor augmentation of human capital and the finance-driven allocative efficiency augmentation of physical capital enable us to build production frontiers in the $\hat{y}-\hat{k}$ space, where $\hat{y}=Y / \hat{L}$ and $\hat{k}$ $=K \cdot F / \hat{L}$ represent the ratio of output to effective labor and the ratio of efficiency units of physical capital to effective labor, respectively. Figure 3 superimposes the 1965 and 2005 technology frontiers under the assumption of no technological regress. One remarkable feature that derives from Figure 3 is the fact that the production frontier shifts upwards from 1965 to 2005 , but not by the same proportion for every value of $\hat{k}$. This implies that technological change is not Hicks-neutral. Rather, we observe that the largest shifts of the production frontier occur at high levels of capitalization, as in KR and HR.

[Insert Figure 3 about here]

\section{Quinquepartite Decomposition of Labor Produc- tivity Change}

\subsection{Conceptual Decomposition}

We decompose labor productivity growth between base $(b)$ and current $(c)$ points in time into components attributable to (1) efficiency changes (catching-up), (2) technological change, (3) physical capital deepening, (4) human capital accumulation and (5) allocative efficiency from financial development. We first note that constant returns to scale allows us to construct the production-frontiers in $\hat{y} \times \hat{k}$ space, where $\hat{y}=Y / \hat{L}$ and $\hat{k}=\hat{K} / \hat{L}$. Since by definition the efficiency index is simply the ratio of actual to potential output evaluated at the actual input quantities, the potential outputs per efficiency units of labor in the two periods are given by $\bar{y}_{b}\left(\hat{k}_{b}\right)=\hat{y}_{b} / e_{b}$ and $\bar{y}_{c}\left(\hat{k}_{c}\right)=\hat{y}_{c} / e_{c}$, where $e_{b}$ and $e_{c}$ are the values of the efficiency indexes in the respective periods as calculated in (7) above. Accordingly,

$$
\frac{\hat{y}_{c}}{\hat{y}_{b}}=\frac{e_{c}}{e_{b}} \cdot \frac{\bar{y}_{c}\left(\hat{k}_{c}\right)}{\bar{y}_{b}\left(\hat{k}_{b}\right)} .
$$

Define four different levels of efficiency units of capital per efficiency level of labor. Let $\tilde{k}_{c}^{F H}=K_{c} F_{b} /\left(L_{c} H_{b}\right)$ denote the ratio of capital to labor measured in efficiency units under the counterfactual assumption that both human capital and financial development had not changed from their base period, $\tilde{k}_{c}^{H}=K_{c} F_{c} /\left(L_{c} H_{b}\right)$ the ratio of capital to labor measured in efficiency units under the counterfactual assumption that only human capital remained at its base-period level, $\tilde{k}_{b}^{F H}=K_{b} F_{c} /\left(L_{b} H_{c}\right)$ the ratio of capital to labor measured in efficiency units under the counterfactual assumption that both human capital and financial development were equal to their current-period levels, and $\tilde{k}_{b}^{H}=K_{b} F_{b} /\left(L_{b} H_{c}\right)$ the ratio 
of capital to labor measured in efficiency units under the counterfactual assumption that only human capital was equal to its current-period level. Then $\bar{y}_{b}\left(\tilde{k}_{c}^{F H}\right), \bar{y}_{b}\left(\tilde{k}_{c}^{H}\right)$ are the potential outputs per efficiency unit of labor at $\tilde{k}_{c}^{F H}$ and $\tilde{k}_{c}^{H}$ using the base-period technology, and $\bar{y}_{c}\left(\tilde{k}_{b}^{F H}\right), \bar{y}_{c}\left(\tilde{k}_{b}^{H}\right)$ are the potential outputs per efficiency unit of labor at $\tilde{k}_{b}^{F H}$ and $\tilde{k}_{b}^{H}$ using the current-period technology. By multiplying the numerator and denominator of (8) alternatively by $\bar{y}_{b}\left(\hat{k}_{c}\right) \bar{y}_{b}\left(\tilde{k}_{c}^{F H}\right) \bar{y}_{b}\left(\tilde{k}_{c}^{H}\right)$ and $\bar{y}_{c}\left(\hat{k}_{b}\right) \bar{y}_{c}\left(\tilde{k}_{b}^{F H}\right) \bar{y}_{c}\left(\tilde{k}_{b}^{H}\right)$, we obtain two alternative decompositions of the growth of $\hat{y}$

$$
\frac{\hat{y}_{c}}{\hat{y}_{b}}=\frac{e_{c}}{e_{b}} \cdot \frac{\bar{y}_{c}\left(\hat{k}_{c}\right)}{\bar{y}_{b}\left(\hat{k}_{c}\right)} \cdot \frac{\bar{y}_{b}\left(\tilde{k}_{c}^{F H}\right)}{\bar{y}_{b}\left(\hat{k}_{b}\right)} \cdot \frac{\bar{y}_{b}\left(\hat{k}_{c}\right)}{\bar{y}_{b}\left(\hat{k}_{c}^{H}\right)} \cdot \frac{\bar{y}_{b}\left(\hat{k}_{c}^{H}\right)}{\bar{y}_{b}\left(\tilde{k}_{c}^{F H}\right)},
$$

and

$$
\frac{\hat{y}_{c}}{\hat{y}_{b}}=\frac{e_{c}}{e_{b}} \cdot \frac{\bar{y}_{c}\left(\hat{k}_{b}\right)}{\bar{y}_{b}\left(\hat{k}_{b}\right)} \cdot \frac{\bar{y}_{c}\left(\hat{k}_{c}\right)}{\bar{y}_{c}\left(\tilde{k}_{b}^{F H}\right)} \cdot \frac{\bar{y}_{c}\left(\tilde{k}_{b}^{H}\right)}{\bar{y}_{c}\left(\hat{k}_{b}\right)} \cdot \frac{\bar{y}_{c}\left(\tilde{k}_{b}^{F H}\right)}{\bar{y}_{c}\left(\tilde{k}_{b}^{H}\right)} .
$$

The growth of productivity, $y_{t}=Y_{t} / L_{t}$, can be decomposed into the growth of output per efficiency unit of labor and the growth of human capital, as follows:

$$
\frac{y_{c}}{y_{b}}=\frac{H_{c}}{H_{b}} \cdot \frac{\hat{y}_{c}}{\hat{y}_{b}} .
$$

Combining (9) and (10) with (11), we obtain

$$
\begin{aligned}
\frac{y_{c}}{y_{b}} & =\frac{e_{c}}{e_{b}} \cdot \frac{\bar{y}_{c}\left(\hat{k}_{c}\right)}{\bar{y}_{b}\left(\hat{k}_{c}\right)} \cdot \frac{\bar{y}_{b}\left(\tilde{k}_{c}^{F H}\right)}{\bar{y}_{b}\left(\hat{k}_{b}\right)} \cdot\left[\frac{\bar{y}_{b}\left(\hat{k}_{c}\right)}{\bar{y}_{b}\left(\hat{k}_{c}^{H}\right)} \cdot \frac{H_{c}}{H_{b}}\right] \cdot \frac{\bar{y}_{b}\left(\hat{k}_{c}^{H}\right)}{\bar{y}_{b}\left(\tilde{k}_{c}^{F H}\right)} \\
& \equiv E F F \times T E C H^{c} \times K A C C^{b} \times H A C C^{b} \times F K A C C^{b}
\end{aligned}
$$

and

$$
\begin{aligned}
\frac{y_{c}}{y_{b}} & =\frac{e_{c}}{e_{b}} \cdot \frac{\bar{y}_{c}\left(\hat{k}_{b}\right)}{\bar{y}_{b}\left(\hat{k}_{b}\right)} \cdot \frac{\bar{y}_{c}\left(\hat{k}_{c}\right)}{\bar{y}_{c}\left(\tilde{k}_{b}^{F H}\right)} \cdot\left[\frac{\bar{y}_{c}\left(\tilde{k}_{b}^{H}\right)}{\bar{y}_{c}\left(\hat{k}_{b}\right)} \cdot \frac{H_{c}}{H_{b}}\right] \cdot \frac{\bar{y}_{c}\left(\tilde{k}_{b}^{F H}\right)}{\bar{y}_{c}\left(\tilde{k}_{b}^{H}\right)} \\
& \equiv E F F \times T E C H^{b} \times K A C C^{c} \times H A C C^{c} \times F K A C C^{c}
\end{aligned}
$$

These identities decompose the growth of labor productivity in the two periods into changes in efficiency, technology, the capital-labor ratio, human capital accumulation and financial development. The decomposition in (9) measures technological change by the shift in the frontier in the output direction at the current-period effective capital to effective labor ratio, whereas the decomposition in (10) measures technological change by the shift in the frontier in the output direction at the base-period effective capital to effective labor ratio. Similarly, (12) measures the effect of physical, human capital accumulation, and financial development along the base-period frontier, whereas (13) measures the effect of physical, human capital accumulation, and financial development 
along the current-period frontier.

These two decompositions do not yield the same results unless the technology is Hicks neutral. In other words, the decomposition is path dependent. This ambiguity is resolved by adopting the "Fisher Ideal" decomposition. This is based on geometric averages of the two measures of the effects of technological change, capital deepening, human capital accumulation and financial development and obtained mechanically by multiplying the numerator and denominator of $(8)$ by $\left(\bar{y}_{b}\left(\hat{k}_{c}\right) \bar{y}_{b}\left(\tilde{k}_{c}^{F H}\right) \bar{y}_{b}\left(\tilde{k}_{c}^{H}\right)\right)^{1 / 2}\left(\bar{y}_{c}\left(\hat{k}_{b}\right) \bar{y}_{c}\left(\tilde{k}_{b}^{F H}\right) \bar{y}_{c}\left(\tilde{k}_{b}^{H}\right)\right)^{1 / 2}$ :

$$
\begin{aligned}
\frac{y_{c}}{y_{b}}= & E F F \times\left(T E C H^{b} \cdot T E C H^{c}\right)^{1 / 2} \times\left(K A C C^{b} \cdot K A C C^{c}\right)^{1 / 2} \\
& \times\left(H A C C^{b} \cdot H A C C^{c}\right)^{1 / 2} \times\left(F K A C C^{b} \cdot F K A C C^{c}\right)^{1 / 2} \\
\equiv & E F F \times T E C H \times K A C C \times H A C C \times F K A C C .
\end{aligned}
$$

\subsection{Empirical Results}

For comparison purposes, we present the results of the decomposition both with and without financial development. The change in labor productivity of each country is reported in the second column of Table 4, while the contributions in percentage terms of changes in each of the five components appear in columns 3 to $7 .{ }^{23}$ Likewise, the first row for each country reports the results from the quinquepartite decomposition, while the second row omits the contribution of financial development.

\section{[Insert Table 4 about here]}

The analysis based on the quinquepartite decomposition substantially modifies the outcomes when financial development is not incorporated. We find that, on average, a substantial part of the productivity growth attributable to physical capital accumulation should, instead, be attributed to the allocative efficiency-enhancing role of financial development. On average, the contribution of physical capital accumulation to the $112 \%$ labor productivity change falls substantially from 71 to $52 \%$. This reduction is almost matched by the productivity contribution of financial development, which equals $15 \%$. The contributions from human capital accumulation and technological progress slightly increase from 21.5 to $26 \%$, and from 11.5 to $13 \%$, respectively. In addition, the incorporation of financial development uncovers higher inefficiency due to larger efficiency losses (-8.7 vs. $-3.9 \%$ ) over the 40 -year period. Hence, part of the productivity change attributable to lower efficiency losses should, instead, be assigned to the allocative efficiency-enhancing effect of financial intermediaries. This accords with the theoretical model and empirical

\footnotetext{
${ }^{23}$ These contributions in percentage terms can be easily transformed into indices using the formula
} $(P E R C E N T A G E / 100+1)$ so that Equation 14 holds. 
findings presented by Aghion et al. (2005), who stressed the pivotal role for high levels of financial development in bringing technological catch-up to the best-practice frontier. ${ }^{24}$

It is also interesting to note that for some countries like Bolivia, Chile and Kenya, financial development emerges as the main growth engine, while for Canada, Egypt, India, Nepal, South Africa, Sri Lanka, Switzerland, Thailand and the U.S., financial development appears to be the second major contributor to productivity growth. In addition, financial development is the third main driver of labor productivity change (though with a contribution very close to the second major contributor) in Iceland, Malaysia, Mauritius, New Zealand, Panama, Philippines, Trinidad and Tobago, the U.K. and Uruguay. This indicates that it is not only the mere accumulation of physical capital that matters for productivity growth, but also the efficiency with which resources are allocated to the most productive use.

Table 5 presents mean changes in labor productivity along with the contribution to productivity change of the five components for five country groups. ${ }^{25}$ The OECD group exhibits above-average productivity growth due to higher technological progress than the world average, while the contributions of physical capital accumulation and financial development appear below average. Regarding the Asian Tigers, productivity has almost quadrupled due to the high contribution from physical capital accumulation and financial development in Malaysia and Thailand, the efficiency gains in Japan and Singapore, ${ }^{26}$ and the slightly above-average contributions from technological progress and human capital accumulation. The poor growth performance in Latin America is caused primarily by large efficiency losses and near zero technological progress. This appears to counteract the near-average contribution of factor accumulation and financial development. The dismal Africa's performance is caused by large efficiency losses and almost zero technological

${ }^{24}$ For Aghion et al. (2005), financial underdevelopment takes the form of an agency problem that limits the innovators' access to external finance. The specific mechanism implies that successful innovators can defraud their creditors by hiding their profits from innovating, at a cost that rises with the level of financial development.

25 The results for different country groupings should be taken as suggestive, but never as conclusive given the small size of some of the groups.

26 According to Shin (1996), the basis for Japan's catching-up to the forerunners (the UK and the U.S.) was institutional development and the technological advancement caused by internal knowledge creation through reverse engineering and in-house R\&D. The building of a successful innovation system was helped by the import of technology in the 1950s and 1960s as well as by the advanced educational system and enterprise training. Interestingly, postwar protection policy limited the role of foreign direct investment (FDI) in Japan's catch-up process. Rather the opposite, Japan has increased its share of overseas investment, mainly in other newly industrialized Asian countries and more recently in the ASEAN countries due to their lower wages (see Edgington and Hayter (2000)). Though also important in Japan, particularly before 1980, export promotion of manufactured goods has been the main driving force for the catch-up process of Singapore since the change in industrial policy from import substitution in the 1960s. By the mid-1990s, Singapore became both trade and service centers (particularly in banking). According to Lim and McAleer (2002), rapid inflows of FDI into Singapore, bringing advanced technology and managerial skills, in addition to a stable macroeconomic environment were also key to the catching-up process. 
progress, with physical capital deepening and financial development contributing slightly above the world average. Finally, it is important to note that financial development has contributed relatively less to productivity growth in advanced countries (as indicated by the mean OECD figures and that of Japan) relative to less developed and emerging economies (as captured by the non-OECD category excluding Japan). Therefore, other things being equal, less developed countries in the sample appear, on average, to have benefited more from financial development. ${ }^{27}$

\section{[Insert Table 5 about here]}

In order to have a preliminary picture about which of these productivity growth components may have contributed to narrowing down the productivity gap between rich and poor countries, we plotted the five components against output per worker in 1965 . GLS regressions do not support the existence of a statistically significant reduction of productivity disparities across countries. Technological progress appears to have substantially widened international productivity disparities, thus counteracting the tendency for physical capital accumulation and financial development to narrowing down cross-country productivity inequalities. ${ }^{28}$ Since these preliminary conclusions are based on first-moment characterizations of the productivity distribution and are vulnerable to Quah's critique, we now turn to examine the evolution of the entire cross-section distribution of labor productivity.

\section{Distributional Analysis}

We now shift the focus to examine the degree to which each of the five components of productivity change accounts for the shifts in the productivity distribution. Figure 4 presents a plot of the distributions of labor productivity for our sample of 57 countries in 1965 and 2005. The solid and dashed curves represent the distributions in both years, with their corresponding mean values shown as vertical lines. By visually inspecting both distributions we observe that (1) there is a transformation from unimodality to bimodality in the productivity distribution, (2) there is a substantial rise in average levels of output per worker over the 40-year period and (3) there is a significant rise in the dispersion of the distribution.

\section{[Insert Figure 4 about here]}

\footnotetext{
27 This does not necessarily imply that financial development is good in all early stages. If we conceive growth as a dynamic process along the lines of Galor (2005)'s unified growth theory, it is conceivable that financial development is important, but additional conditions may need to be met before financial development becomes beneficial.

28 To conserve space, we do not report these plots, which are available in the unpublished appendix.
} 
The 2005 distribution clearly reflects the emergence of a mode entailing a large gain in probability mass at the upper-middle-productivity level, while a sharp fall in probability mass at lower-middle-productivity levels. This appears to fully accord with Quah's twinpeaks convergence hypothesis that postulates that the middle-income group of countries vanishes due to their shifts towards the upper end of the distribution, thus giving rise to the richer peak. Applying the test developed by Silverman $(1981)^{29}$ to both productivity distributions, we fail to reject the null hypothesis of a single mode for the 1965 distribution $(p$-value $=0.740)$, while we reject the null of one mode at the $1 \%$ significance level $(p$ value $=0.000$ ) for the 2005 distribution. ${ }^{30}$

In what follows, we will characterize the polarization of the labor productivity distribution as well as the rise in dispersion in terms of the quinquepartite decomposition results, paying particular attention to the financial development component. In order to separate the effect of each of the five components on the change in mean productivity from the transformation of the distribution in terms of shape and dispersion, we follow HR by considering mean-preserving shifts of the productivity distribution. Hence, from now onwards we work with the 1965 and 2005 distributions of deviations from the productivity mean $y_{t}-\widetilde{y}$, where $\widetilde{y}$ is the productivity mean in year $t$, thereby implying that each distribution has zero mean.

By using the quinquepartite decomposition of productivity growth, we rewrite Equation 14 as follows:

$$
y_{c}=(E F F \times T E C H \times K A C C \times H A C C \times F K A C C) \times y_{b},
$$

where $b=1965$ and $c=2005$. Accordingly, the labor productivity distribution in 2005 can be constructed by consecutively multiplying the labor productivity distribution in 1965 by each of the five components. To isolate the impact of each component, we create counterfactual distributions by sequentially introducing each of these factors. They can then be compared to the actual 2005 distribution.

In each panel of Figures 5-7, the solid curve is the estimated 1965 distribution of output per worker and the dashed curve represents the estimated 2005 distribution, whereas the counterfactual distributions are shown as dotted curves. For instance, one can assess the mean-preserving shift of the labor productivity distribution due solely to efficiency changes (catching-up) by examining the counterfactual distribution of the variable:

$$
y^{E}=E F F \times y_{b}
$$

\footnotetext{
${ }^{29}$ Here and below, we employ the calibrated version of the Silverman test by Hall and York (2001), which exhibits better properties in finite samples.

${ }^{30}$ We discard the possibility of more than two modes in the 2005 distribution, since we fail to reject the null hypothesis of two modes versus the alternative of more than two modes $(p$-value $=0.744)$.
} 
with its mean extracted, and assuming no technological change, no physical and human capital accumulation and no financial development. This is shown in Panel A of Figure 5. We then include sequentially more components in the counterfactual distribution to isolate their effects. Hence, when we include physical capital accumulation in $y^{E}$, we have:

$$
y^{E K}=(E F F \times K A C C) \times y_{b}=K A C C \times y^{E},
$$

drawn in Panel B of Figure 5. The additional effect of human capital accumulation on the distribution $y^{E K}$ can be assessed by multiplying by HACC such that:

$$
y^{E K H}=(E F F \times K A C C \times H A C C) \times y_{b}=H A C C \times y^{E K},
$$

drawn in Panel C. Finally, Panel D incorporates the effect of financial development in $y^{E K H}$ such that:

$$
y^{E K H F}=(E F F \times K A C C \times H A C C \times F K A C C) \times y_{b}=F K A C C \times y^{E K H},
$$

[Insert Figure 5 about here]

We perform the calibrated version of the Silverman (1981) multimodality test to statistically assess which component (or set of components) causes bimodality in the 2005 productivity distribution. We use the bootstrapped version of the Li (1996) test to distinguish the component (set of components) that contributes to overall changes in the distribution of labor productivity, paying particular attention to variations in dispersion. ${ }^{31}$ The Silverman (1981) and Li (1996) tests' results are reported in Tables 6 and 7, respectively.

Table 6 shows evidence that efficiency changes alone can account for the emergence of bimodality in the distribution. In fact, rows 3-7 in Table 6 introduce just one of the five components separately, and we are only able to reject the null hypothesis of unimodality at the $5 \%$ significance level or better for row 3 of Table $6 .{ }^{32}$ Not surprisingly, when we incorporate the contribution of the four other components one at a time to that of efficiency changes, we are equally able to reject the null of unimodality at the $1 \%$ level (rows 8 to 11 of Table 6). Likewise, when efficiency changes are interacted with the contribution of either two other components (rows 18 to 23 of Table 6) or three other components (rows 28 to 31 of Table 6 ), the strong rejection of the null of a single mode remains.

\footnotetext{
${ }^{31}$ If $f$ and $g$ are these distributions, this statistic tests the null hypothesis $H_{0}: f(x)=g(x)$ for all $x$, against the alternative $H_{1}: f(x) \neq g(x)$ for some $x$. See the (unpublished) methodological appendix for a more detailed account of the construction of this test.

${ }^{32}$ In contrast, in HR analysis, efficiency changes needed the help of physical capital or human capital accumulation to reject the unimodality null hypothesis at the $5 \%$ significance level.
} 


\section{[Insert Table 6 about here]}

Figure 5 clearly backs up the above results for the ordering given in Equations 16 to 19. Visual inspection of Panel A appears to indicate the emergence of bimodalism in this counterfactual distribution due only to the effect of international efficiency changes. This is further supported by the Silverman test result in row 3 of Table 6. Panels B to D incorporate sequentially the effects of physical capital deepening, human capital accumulation and financial development. These panels exhibit even more clearly the presence of twin peaks in the international productivity distribution, with a higher distance between the rich and poor modes. This in turn illustrates the strong rejections of the null of a single mode with the Silverman test in rows 9, 21 and 31 of Table 6.

\section{[Insert Table 7 about here]}

In Figure 6 we change the sequence of introducing the factors. We start with physical capital accumulation, followed by technological change, efficiency changes and human capital accumulation. Panel A shows that the incorporation of physical capital accumulation hardly changes the shape of the 1965 distribution, illustrating the test result in row 5 of Table 6 . Panel B further incorporates the effect of technological progress, but bimodalism does not emerge yet. This appears in line with the test result in row 12 of Table 6. However, increased dispersion is a distributional feature that emerges when technological change is introduced. We will come to this point below. And again, it is not until the introduction of the contribution of efficiency changes in Panel $\mathrm{C}$ that we are able to observe the emergence of twin peaks. This corroborates the test result in row 18 of Table 6 . When we further incorporate the effect of human capital accumulation bimodalism is even more apparent, as the distance between the rich and the poor becomes higher. This supports the test result in row 28 of Table 6 that strongly rejects the null hypothesis of a single mode. ${ }^{33}$

\section{[Insert Figure 6 about here]}

The Li (1996) test provides evidence that technological change, when combined with either physical or human capital accumulation or financial development, is the primary contributor to the overall change in the shape and dispersion of the productivity distribution from 1965 to 2005 (rows 11 to 13 of Table 7). This sharply contrasts with HR findings pointing to physical capital accumulation as the main driving force in accounting for the overall change in the distribution. In addition, most other instances where the null hypothesis of distributional equality clearly fails to be rejected (in these cases at higher

\footnotetext{
${ }^{33}$ Essentially the same results follow when we alter the ordering in the addition of the contribution of each component to the mix.
} 
significance levels than 5\%) occur when technological change is combined with either two of those components (rows 23 to 25 of Table 7 ) or the three of them (row 31 of Table 7).

These facts are broadly illustrated in Figure 7 for the following sequence: technological change, financial development, physical capital accumulation and efficiency changes. As shown in Panel A, the dispersion of the distribution substantially increases after incorporating technological change. Panels $\mathrm{B}$ and $\mathrm{C}$ that sequentially introduce the effect of financial development and physical capital accumulation also exhibit a further increase in dispersion, thus approaching the level of the 2005 distribution. In both cases, as supported by the test results in rows 13 and 24 of Table 7, we fail to reject the null hypothesis of identity of the counterfactual and actual 2005 distributions at the $1 \%$ and $5 \%$, respectively. Finally, Panel D incorporates the additional effect of efficiency changes that brings about bimodalism. This is clearly supported by the rejection of the null of a single mode for the specification with the four components (row 29 compared to row 25 of Table 6 ).

\section{[Insert Figure 7 about here]}

In sum, the evidence from the counterfactual distributional analysis and statistical tests in Tables 6 and 7 indicates that polarization is primarily driven by efficiency changes, while the increased dispersion exhibited by the productivity distribution from 1965 to 2005 is explained predominantly by technological change, with some help from financial development and/or physical and human capital accumulation.

\section{Sensitivity Analyses}

Having presented the results for a specific set of financial efficiency augmentation factors obtained from the regression of net interest margin on CREDIT1 for a sample of 57 countries over the period 1965-2005, we now shift the focus to present the summary results from a wide array of sensitivity analyses. These exercises allow us to check the robustness of our findings to the following changes: (1) the inclusion of alternative sets of financial efficiency augmentation factors obtained from the different combinations between the two financial efficiency measures and the four financial development proxies considered, (2) the investigation of the shorter period 1965-1990 analyzed by HR, and (3) the incorporation of institutional variables thought to be complementary to financial development, which results in a sexapartite decomposition of labor productivity growth.

Due to space limitations, we present only the aggregate results (average efficiency scores and the contribution of each component to productivity change). The reader can find the detailed results of the country-specific efficiency scores and production frontier calculations, the decomposition of productivity change and the distributional analysis in an unpublished appendix available in the authors' homepages. 


\subsection{Alternative financial efficiency augmentation factors}

Table 8 shows the same tendency for the average efficiency score to decrease (particularly in 2005) after the incorporation of the alternative financial efficiency augmentation factors as found in our baseline results. Likewise, the average contribution to productivity growth attributable to physical capital accumulation substantially falls from about 71 to $54 \%$ or less. This sliced contribution almost matches the contribution assigned to the allocative efficiency-enhancing role of financial development, which ranges from $14 \%$ with CREDIT2 to $15-17 \%$ with PRIVY and LLY. As with our baseline results, the contribution of efficiency changes falls, which indicates that efficiency changes capture the favorable effect of financial development on the catching-up to the frontier. Furthermore, the contribution from technological change and human capital accumulation exhibit a minor increase. From the (unreported) distributional analysis, we find again that efficiency changes alone are able to drive bimodality in the 2005 distribution, while technological progress with the help of financial development and/or physical and human capital accumulation are crucial in explaining the increased dispersion in the 2005 distribution.

\section{[Insert Table 8 about here]}

In order to provide the share of overall productivity growth attributed to each component on a $100 \%$ scale, we take logs of both sides of our decomposition (14). We then calculate the percentages of the mean contributions of respective factors to the log of the productivity ratios, with $b$ equaling the first year of the time period and $c$ the final year, and compute averages across the countries included in the sample. As shown in Table 9 , the mean percentage contribution of financial development to productivity growth over the period 1965-2005 appears to be about 20\%. This roughly corresponds to the reduction (from about 70 to $54 \%$ ) that the contribution of capital deepening experiences when financial efficiency augmentation factors are incorporated. Still, physical capital accumulation appears to be the main growth engine over the 40-year period, while human capital accumulation continues as the second main driver of productivity growth, with a contribution of about $34 \%$. In addition, about $18 \%$ of overall growth can be attributed to technological change, while efficiency changes have retarded growth by a range between 25 and $30 \%$.

[Insert Table 9 about here]

\section{$6.2 \quad 1965-1990$ period}

Fairly similar results are obtained when we restrict the analysis to the period 1965-1990 analyzed by HR. As shown in Panel D of Table 9, the percentage contribution attributable 
to financial development equals $18.5 \%$, while the percentage contribution of physical capital accumulation falls from $84 \%$ to about $68 \%$ after incorporating financial development. As with the full period analysis, the contributions from human capital accumulation and technological change slightly increase from 29.5 to $34 \%$, and from 13.5 to $16 \%$, respectively. Again, the incorporation of financial development uncovers higher inefficiency, with a percentage contribution from efficiency changes shifting from -27 to $-36 \%$. Similar results follow when we employ alternative sets of financial efficiency augmentation factors obtained using CREDIT2, PRIVY and LLY. Distributional analysis suggests that bimodality is again solely driven by efficiency changes, and increased dispersion is caused by technological change, with some help from human and physical capital accumulation, and to a less extent from financial development.

\subsection{Institutional and legal environment}

We now proceed to assess the effect of some institutional and legal variables that are thought to be complementary to financial development. The incorporation of institutional variables into our previous decomposition framework results in a sexapartite decomposition of labor productivity change into six components. It is well-documented that a well-functioning legal system leading to a high degree of protection of private property rights and an effective enforcement of contracts is key to the efficient operation of financial contracts supporting commercial and financial transactions as well as to the development of a well-functioning financial system (Levine (1998), Levine et al. (2000), Beck et al. (2003) and Acemoglu and Johnson (2005)). Central to this complementarity is the contractual nature of financial transactions. As a matter of fact, La Porta et al. (1997) developed a dataset on legal factors for 49 countries to show that legal systems that better protect the rights of individual private investors and more effectively enforce contracts lead to more developed financial systems.

In assessing the productivity contribution of institutional and legal factors complementary to financial development, we proceed in an analogous way to what we did for financial development. More specifically, we first regress financial efficiency measures such as the log of the inverse of net interest margin and overhead costs on financial development and institutions. We then use an exponential function to construct institutions-driven financial efficiency augmentation factors such that $f\left(I N S T_{t j}\right)=e^{\zeta\left(I N S T_{t j}\right)}$, where $\zeta$ is a linear function that depends on the estimated effect of institutional and legal factors on financial efficiency. Finally, we augment physical capital by financial development and institutions-driven financial efficiency factors. To motivate this modeling strategy, we adhere to Acemoglu and Johnson (2005), who stress that cross-country differences in laws and the way they are implemented can generate large differences in the costs of enforc- 
ing financial contracts and in turn in the efficiency with which funds are assigned to the most productive use. This occurs because in a country characterized by weak financial contracting institutions, there will be a large increase in interest rate spreads (resulting in lower financial intermediary efficiency) so that lenders can be compensated in the event of a debtor's default. ${ }^{34}$ Thus, better contract enforcement as captured by the law and order measure employed below will arguably be associated with a more efficient allocation of resources.

Likewise, the presence of a strong system of property rights protection is necessary for an efficient allocation of resources. In the absence of checks and balances on the state and powerful elites, individual investors will not have the necessary property rights security as to invest in some high-risk but high-return projects. This has been recently shown empirically by Claessens and Laeven (2003). Using the industry-level framework of Rajan and Zingales (1998), they provide evidence that stronger property rights protection leads to higher growth via improved asset allocation to the most productive uses. This is captured through a higher share of investment in intangible assets that enters the specification interacting with institutional measures of property rights protection. This growth effect appears comparable in magnitude to that deriving from financial development.

In line with previous studies we employ four main institutional variables, which are thought to affect the efficiency in assets allocation. These variables are Investment Profile, Law and Order, Democratic Accountability and Bureaucratic Quality, which are all obtained from the International Country Risk Guide produced by the Political Risk Services Group (2011) and span over the period 1984-2005. This is the reason for restricting this robustness exercise to this period. Investment Profile is an assessment of factors affecting the risk to investment and consists of three main components: contract viability/expropriation, profits repatriation and payment delays, each of which is assigned a score between 0 (high risk) and 4 (very low risk). This variable comprises two key private property rights measures covered by the old version of this dataset (see Knack and Keefer (1995)): expropriation risk of assets by government and contract repudiation of government. The former measures the possibility of property confiscation and forced nationalization, whereas the latter captures the possibility that foreign businesses and contractors face the risk of a modification in a contract taking the form of repudiation, postponement or reduction of the government's obligation.

\footnotetext{
34 The endogenous growth model of Chakraborty and Ray (2006) provides a theoretical illustration showing that better functioning legal systems and higher institutional quality make financial contracts easier to enforce. This results in a large reduction in the banks' monitoring costs -incurred to resolve moral-hazard problems at the firm level- and in the interest rate spread. This stems from the fact that better protection of individual investors' rights and effective rule of law enforcement reduce the private benefits that a negligent manager can obtain even if monitoring of firms' outcomes is not present. Along similar lines, financial contracts lowering monitoring and enforcement costs lead to more efficient investment (von Thadden (1995)).
} 
Law and Order is normally used as a measure of the strength of the legal system in enforcing contracts, giving indications of a country's court efficiency and the degree to which a country adheres to the rule of law. This variable is composed of two elements: Law that assesses the strength and impartiality of the legal system, and Order that provides an assessment of popular observance of the law. Each of these components is assigned a score between 0 (high risk) and 3 (very low risk). Democratic Accountability is an assessment of the degree of responsiveness of a country's government to its citizens, giving indications of the degree of political order in a country. The more responsive a government is to its people, the less likely it is that it will fall. The six points assigned to this variable are awarded on the basis of the type of governance enjoyed: alternating democracy, dominated democracy, de facto one-party state, de jure one-party state and autarchy. A higher score (very low risk) is given to alternating democracies while a lower score (high risk) to autarchies. Finally, Bureaucratic Quality measures a country's institutional strength and quality of its institutions. A score of 4 (low risk) is assigned to countries where bureaucracy can govern without drastic revisions of policy when governments change, due to its independence from political pressure. In contrast, a score of 0 is assigned to high-risk countries where bureaucracy is closely tied to the government in office.

The results of the sexapartite decomposition are reported in Table 10. Remarkably, the percentage contribution to productivity change of financial development remains fairly unchanged when we incorporate the efficiency-enhancing effect of institutions. This contribution ranges from $22.37 \%$ for the specification including Investment Profile to $17 \%$ for the specification with Law and Order. Regarding the percentage contribution of institutions, we find evidence of some effect from Law and Order (18.65\%), Bureaucratic Quality (14.29\%) and Democratic Accountability (11.17\%), whereas the impact from Investment Profile (1.32\%) is negligible. Panel A of Table 10 indicates that most part of the fall in the percentage contribution of physical capital accumulation takes place after the incorporation of financial development rather than institutions. For instance, the percentage contribution from capital deepening falls from 40.5 to about $23 \%$ when financial development is incorporated, and only to $22.6 \%$ when Investment Profile is further included. Something similar occurs for the other institutional variables, particularly for Democratic Accountability whose inclusion leads to a fall in the percentage contribution of physical capital accumulation from about 23 to $20.72 \%$. Overall, the incorporation of financial development appears to reduce the percentage contribution of capital deepening by about one half (from 40 to about 20\%) over the period 1984-2005. In addition, human capital becomes the main engine of productivity growth with a percentage contribution of about $30 \%$, closely followed by technological change that contributes to productivity change by at least $22 \%$.

We further extend the production frontier framework by introducing two institutional 
variables rather than one, resulting in a septipartite conceptual decomposition of labor productivity, which, in addition to gauging the effects of efficiency change, technological change, physical and human capital accumulation, and financial development, also distinguishes between the effects of two institutional indices. As shown in Table 10, it is remarkable that the percentage contribution of financial development remains fairly unchanged after the incorporation of two institutional indicators. This contribution ranges from $15 \%$ for the specification with Law and Order and Bureaucratic Quality to 21.5\% for the specification with Investment Profile and Democratic Accountability.

\section{[Insert Table 10 about here]}

The evidence gathered through these sensitivity analyses clearly corroborates our main results. When we fail to incorporate financial development, the large effect of physical capital accumulation on labor productivity masks the important role of well-functioning financial institutions in raising productivity growth by improving the efficiency of capital allocation.

\section{Conclusion}

This paper has extended the literature on finance and growth by incorporating estimates of the effect of financial development on financial intermediation efficiency into the nonparametric production frontier approach previously employed by KR and HR. This in turn has enabled us to provide theoretical foundations for the extension of the HR quadripartite decomposition of labor productivity growth into components attributable to efficiency change, technological change, and physical and human capital accumulation, by introducing financial development as a fifth component. Arguably, this framework is ideal for determining the impact of financial development on productivity growth and convergence.

Using several estimates to capture the efficiency-enhancing effect of financial intermediaries, our results have significantly modified the outcomes relative to the case where financial development is omitted. First, we have found that a substantial part of the productivity growth attributable to physical capital accumulation should, instead, be attributed to the allocative efficiency-enhancing role of financial development. Second, this reduction is almost matched by the productivity contribution of financial development. Third, the augmentation of physical capital with financial efficiency factors has uncovered higher inefficiency, i.e. higher distance from the best-practice frontier. Fourth, income polarization is solely driven by efficiency changes capturing movements toward or away from the frontier. Fifth, the increased dispersion exhibited by the productivity distribution from 1965 to 2005 is accounted for primarily by technological change, accompanied by financial development and/or physical and human capital accumulation. Sixth, financial 
development has contributed relatively less to productivity growth in advanced countries than in developing economies. These results are not sensitive to (1) the use of alternative sets of financial efficiency augmentation factors, (2) the investigation of the shorter period 1965-1990 analyzed by HR, and (3) the incorporation of institutional and legal factors thought to be complementary to financial development.

Overall, we can infer from our analysis that HR, despite accounting for human capital accumulation that reduced the growth contribution of capital deepening by one third (compared to KR findings), still continued overstating the contribution of physical capital accumulation almost by a third. When we restrict the analysis to the period 19842005, the contribution of capital deepening is overstated almost by half. Our analysis has evinced that most of this overstated effect should be attributed to the allocative efficiency-enhancing role of financial intermediaries, which have contributed on average to about $20 \%$ of the overall productivity change over the period 1965-2005. Thus, even if currently markets are going through turbulent times, our analysis has shown that in the long run a well-functioning financial system should be considered a fundamental source of productivity growth by helping allocate capital to the most productive use.

\section{References}

Acemoglu, D. and Johnson, S.: 2005, Unbundling institutions, Journal of Political Economy 113(5), 949-995.

Acemoglu, D. and Zilibotti, F.: 1997, Was prometheus unbound by chance? risk, diversification, and growth, Journal of Political Economy 105(4), 709-775.

Aghion, P., Howitt, P. and Mayer-Foulkes, D.: 2005, The effect of financial development on convergence: Theory and evidence, Quarterly Journal of Economics 120(1), 709775 .

Amaral, P. S. and Quintin, E.: 2010, Limited enforcement, financial intermediation, and economic development: A quantitative assesment, International Economic Review 51(3), 785-811.

Bahegot, W.: 1973, Lombard Street: A Description of the Money Market, E.P. Dutton and Company, 1910 Edition.

Barro, R. J. and Lee, J.-W.: 2010, A new data set of educational attainment in the world, 1950-2010, NBER Working Papers 15902, National Bureau of Economic Research, Inc.

Beck, T., Demirgüç-Kunt, A. and Levine, R.: 2000, A new database on the structure and development of the financial sector, World Bank Economic Review 14(3), 597-605.

Beck, T., Demirgüç-Kunt, A. and Levine, R.: 2010, Financial institutions and markets across countries and over time: The updated financial development and structure database, World Bank Economic Review 24(1), 77-92. 
Beck, T., Demirg-Kunt, A. and Levine, R.: 2003, Law, endowments and finance, Journal of Financial Economics 70, 137-171.

Beck, T., Levine, R. and Loayza, N. V.: 2000, Finance and the sources of growth, Journal of Financial Economics 58(1-2), 261-300.

Bencivenga, V. R. and Smith, B. D.: 1991, Financial intermediation and endogenous growth, Review of Economics Studies 58(2), 195-209.

Bencivenga, V., Smith, B. D. and Starr, R. M.: 1995, Transactions costs, technological choice, and endogenous growth, Journal of Economic Theory 67(1), 153-177.

Buera, F. J., Kaboski, J. P. and Shin, Y.: 2011, Finance and development: A tale of two sectors, American Economic Review forthcoming, 1-37.

Caselli, F. and Feyrer, J.: 2007, The marginal product of capital, Quarterly Journal of Economics 122(2), 535-568.

Chakraborty, S. and Ray, T.: 2006, Bank-based versus market-based financial systems: A growth-theoretic analysis, Journal of Monetary Economics 53, 329-350.

Claessens, S. and Laeven, L.: 2003, Financial development, property rights, and growth, Journal of Finance 58(6), 2401-2436.

de Gregorio, J. and Guidotti, P. E.: 1995, Financial development and intersectoral allocation: A new approach, World Development 23(3), 433-448.

Devereux, M. B. and Smith, G. W.: 1994, International risk sharing and economic growth, International Economic Review 35(3), 535-550.

Diewert, W. E.: 1980, Capital and the theory of productivity measurement, The American Economic Review 70(2), 260-267.

Edgington, D. W. and Hayter, R.: 2000, Foreign direct investment and the flying geese model: Japanese electronics firms in asia-pacific, Environment and Planning A 32, 281304.

Färe, R., Grosskopf, S. and Lovell, C. A. K.: 1985, Production Frontiers, Kluwer-Nijhoff.

Farrell, M. J.: 1957, The measurement of productive efficiency, Journal of the Royal Statistical Society. Series A (General) 120(3), 253-290.

Fisman, R. and Love, I.: 2004, Financial development and intersectoral allocation: A new approach, Journal of Finance 59(6), 2785-2807.

Galetovic, A.: 1996, Specialization, intermediation and growth, Journal of Monetary Economics 38(3), 349-359.

Galor, O.: 2005, From stagnation to growth: Unified growth theory, in P. Aghion and S. Durlauf (eds), Handbook of Economic Growth, Vol. 1A, Elsevier, chapter 4, pp. 171293.

Goldsmith, R. W.: 1969, Financial Structure and Development, Yale University Press. 
Greenwood, J. and Jovanovic, B.: 1990, Financial development, growth, and the distribution of income, Journal of Political Economy 98(5), 1076-1107.

Greenwood, J., Sanchez, J. M. and Wang, C.: 2010a, Financing development: The role of information costs, American Economic Review 100(4), 1875-1891.

Greenwood, J., Sanchez, J. M. and Wang, C.: 2010b, Quantifying the impact of financial development on economic development, Working Paper 15893, National Bureau of Economic Research.

Group, P. R. S.: 2011, International country risk guide: Icrg methodology, Mimeograph, The Political Risk Services. Group. Inc.

Hall, P. and York, M.: 2001, On the calibration of Silvermans test for multimodality, Statistica Sinica 11, 515-536.

Hall, R. E. and Jones, C. I.: 1999, Why do some countries produce so much more output per worker than others?, Quarterly Journal of Economics 114(1), 83-116.

Henderson, D. J. and Russell, R. R.: 2005, Human capital and convergence: A productionfrontier approach, International Economic Review 46(4), 1167-1205.

Heston, A., Summers, R. and Aten, B.: 2011, Penn World Table version 7.0, Center for International Comparisons of Production, Income and Prices, University of Pennsylvania .

Hulten, C. and Wykoff, F. C.: 1996, Issues in the measurement of economic depreciation, Economic Inquiry XXXIV(1), 337-360.

Jayaratne, J. and Strahan, P. E.: 1996, The finance-growth nexus: Evidence from bank branch deregulation, Quarterly Journal of Economics 111(3), 639-670.

King, R. G. and Levine, R.: 1993a, Finance, entrepreneurship, and growth: Theory and evidence, Journal of Monetary Economics 32(3), 513-542.

King, R. G. and Levine, R.: 1993b, Finance and growth: Schumpeter might be right, Quarterly Journal of Economics 108(3), 717-738.

Knack, S. and Keefer, P.: 1995, Institutions and economic performance: Cross-country tests using alternative institutional measures, Economics and Politics 7(3), 207-227.

Kumar, S. and Russell, R. R.: 2002, Technological change, technological catch-up, and capital deepening: Relative contributions to growth and convergence, American Economic Review 92(3), 527-548.

La Porta, R., Lopez-de Silanes, F. and Shleifer, A.: 2002, Government ownership of banks, Journal of Finance 57(1), 265-301.

La Porta, R., Lopez-de Silanes, F., Shleifer, A. and Vishny, R. W.: 1997, Legal determinants of external finance, Journal of Finance 52(3), 1131-1150.

Levine, R.: 1991, Stock markets, growth, and tax policy, Journal of Finance 46(4), 14451465. 
Levine, R.: 1997, Financial development and economic growth: Views and agenda, Journal of Economic Literature 35(2), 688-726.

Levine, R.: 1998, The legal environment, banks and long-run economic growth, Journal of Money, Credit and Banking 30(3), 596-613.

Levine, R.: 2005, Finance and growth: Theory and evidence, in P. Aghion and S. Durlauf (eds), Handbook of Economic Growth, Vol. 1A, Elsevier, chapter 12, pp. 865-934.

Levine, R., Loayza, N. V. and Beck, T.: 2000, Financial intermediation and growth: Causality and causes, Journal of Monetary Economics 46(1), 31-77.

Levine, R. and Zervos, S.: 1998, Stock markets, banks, and economic growth, American Economic Review 88(3), 537-558.

Li, Q.: 1996, Nonparametric testing of closeness between two unknown distribution functions, Econometric Reviews 15, 261-274.

Liberti, J. M. and Mian, A. R.: 2010, Collateral spread and financing development, Journal of Finance 65(1), 147-177.

Lim, L. K. and McAleer, M.: 2002, Economic growth and technological catching-up by singapore to the usa, Mathematics and Computers in Simulation 59, 133-144.

Lucas, R. E.: 1988, On the mechanics of economic development, Journal of Monetary Economics 22(1), 3-42.

McKinnon, Ronald, I.: 1973, Money and Capital in Economic Development, Brookings Institution Press.

Midrigan, V. and Xu, D. Y.: 2010, Finance and misallocation: Evidence from plant-level data, Working paper, New York University.

Moll, B.: 2010, Productivity losses from financial frictions: Can self-financing undo capital misallocation?, Working paper, Princeton University.

Neusser, K. and Kugler, M.: 1998, Manufacturing growth and financial development: Evidence from oecd countries, Review of Economics and Statistics 80(4), 636-646.

Obstfeld, M.: 1994, Risk-taking, global diversification, and growth, American Economic Review 84(5), 1310-1329.

Psacharopoulos, G.: 1994, Returns to investment in education: A global update, World Development 22, 1325-1343.

Quah, D.: 1996a, Convergence empirics across economies with (some) capital mobility, Journal of Economic Growth 1(1), 95-124.

Quah, D.: 1996b, Twin peaks: Growth and convergence in models of distribution dynamics, Economic Journal 106(437), 1045-1055.

Quah, D.: 1997, Empirics for growth and distribution: Stratification, polarization, and convergence clubs, Journal of Economic Growth 2(1), 27-59. 
Rajan, R. G. and Zingales, L.: 1998, Financial dependence and growth, American Economic Review 88(3), 559-586.

Rioja, F. and Valev, N.: 2004, Does one size fit all?: A reexamination of the finance and growth relationship, Journal of Development Economics 74, 429-447.

Romer, P.: 1986, Increasing returns and long-run growth, Journal of Political Economy 94(5), 1002-1037.

Romer, P.: 1990, Endogenous technological change, Journal of Political Economy 98(5), S71-S102.

Saint-Paul, G.: 1992, Technological choice, financial markets and economic development, European Economic Review 36(4), 763-781.

Schumpeter, J. A.: 1912, Theorie der Wirtschaftlichen Entwicklung [The Theory of Economic Development, translated by R. Opie, Cambridge, MA: Harvard University Press, 1934], Dunker \& Humblot.

Sheather, S. J. and Jones, M. C.: 1991, A reliable data based bandwidth selection method for kernel density estimation, Journal of Royal Statistical Society, Series B 53, 683-990.

Shin, J.-S.: 1996, The Economics of Latecomers: Catching-up, Technology Transfer and Institutions in Germany, Japan and South Korea, Routledge.

Silverman, B. W.: 1981, Using kernel density estimates to investigate multimodality, Journal of the Royal Statistical Society, Series B 43, 97-99.

von Bohm-Bawerk, E.: 1891, Positive Theory of Capital, Mcmillan and Company [translated by William A. Smart.

von Thadden, E.-L.: 1995, Long-term contracts, short-term investment and monitoring, Review of Economic Studies 62(4), 557-575.

Wurgler, J.: 2000, Financial markets and the allocation of capital, Journal of Financial Economics 58(1-2), 187-214. 
Table 1: Linking financial efficiency and financial development ${ }^{\mathrm{a}}$

\begin{tabular}{lccccccc}
\hline & \multicolumn{3}{c}{ Net interest margin } & & \multicolumn{3}{c}{ Overhead costs } \\
\cline { 2 - 3 } \cline { 7 - 8 } & $(1)$ & $(2)$ & $(3)$ & & $(1)$ & $(2)$ & $(3)$ \\
\hline Low Region $^{\mathrm{b}}$ & 1.8610 & 1.2383 & 1.0562 & & 0.2690 & -0.4603 & 0.2890 \\
& 0.1616 & 0.3841 & 0.4748 & & 0.8529 & 0.7680 & 0.8532 \\
Middle Region $^{\mathrm{c}}$ & 2.0127 & 1.9855 & 1.8429 & & 1.4080 & 1.3885 & 1.9752 \\
& $<0.0001$ & 0.0003 & 0.0031 & & 0.0048 & 0.0178 & 0.0028 \\
High Region $^{\mathrm{d}}$ & 1.1712 & 1.2336 & 1.1401 & & 0.8549 & 0.8960 & 1.2806 \\
& $<0.0001$ & 0.0001 & 0.0017 & & 0.0012 & 0.0066 & 0.0010 \\
GB70 & & 0.2994 & 0.2968 & & 0.2141 & 0.2247 \\
& & 0.2101 & 0.2180 & & 0.4135 & 0.3766 \\
ly65 & & & 0.0431 & & & -0.1774 \\
& & & 0.6146 & & & 0.0551 \\
Constant & 2.4841 & 2.3537 & 2.0475 & & 2.8287 & 2.7388 & 3.9988 \\
& $<0.0001$ & $<0.0001$ & 0.0036 & $<0.0001$ & $<0.0001$ & $<0.0001$ \\
\hline R-squared & 0.450 & 0.412 & 0.416 & & 0.325 & 0.325 & 0.378 \\
N & 57 & 51 & 51 & & 57 & 51 & 51 \\
Joint significance & $<0.0001$ & 0.0001 & 0.0028 & & 0.0001 & 0.0021 & 0.0004 \\
\hline
\end{tabular}

a The dependent variable is the $\log$ of the inverse of the financial efficiency measure. The coefficients on the financial development regimes (regions) represent the sum of coefficients and the respective numbers below the coefficients are p-values for the sum of coefficients

b Financial development falls into the low region if its value is lower than the $25^{\text {th }}$ percentile of the financial development distribution

${ }^{c}$ Financial development falls into the middle region if its value is between the $25^{t h}$ and $75^{\text {th }}$ percentiles (inclusive) of the financial development distribution

d Financial development falls into the high region if its value is greater than the $25^{\text {th }}$ percentile of the financial development distribution

e $p$-value of the $F$-statistic on the three coefficients on financial development in the main regression. 
Table 2: Financial efficiency augmentation factors

\begin{tabular}{|c|c|c|c|c|c|c|c|}
\hline$\#$ & Country & 1965 & 2005 & $\#$ & Country & 1965 & 2005 \\
\hline 1 & Argentina & 1.114 & 1.114 & 30 & Japan & 2.398 & 3.071 \\
\hline 2 & Australia & 1.226 & 3.181 & 31 & Kenya & 1.156 & 1.575 \\
\hline 3 & Austria & 2.020 & 3.402 & 32 & Malaysia & 1.132 & 3.347 \\
\hline 4 & Belgium & 1.140 & 2.270 & 33 & Mauritius & 1.251 & 2.282 \\
\hline 5 & Bolivia & 1.054 & 2.156 & 34 & Mexico & 1.585 & 1.176 \\
\hline 6 & Burundi & 1.026 & 1.529 & 35 & Morocco & 1.141 & 2.519 \\
\hline 7 & Canada & 1.236 & 6.968 & 36 & Nepal & 1.016 & 1.791 \\
\hline 8 & Chile & 1.106 & 2.321 & 37 & Netherlands & 2.363 & 6.296 \\
\hline 9 & Colombia & 1.208 & 1.667 & 38 & New Zealand & 1.572 & 4.097 \\
\hline 10 & Costa Rica & 1.678 & 1.787 & 39 & Norway & 3.111 & 3.078 \\
\hline 11 & Cote d'Ivoire & 1.214 & 1.146 & 40 & Panama & 1.162 & 2.351 \\
\hline 12 & Cyprus & 2.023 & 6.002 & 41 & Paraguay & 1.088 & 1.189 \\
\hline 13 & Denmark & 1.679 & 6.320 & 42 & Peru & 1.127 & 1.210 \\
\hline 14 & Dominican Rep. & 1.080 & 1.215 & 43 & Philippines & 1.526 & 1.751 \\
\hline 15 & Ecuador & 1.190 & 1.243 & 44 & Portugal & 2.626 & 4.953 \\
\hline 16 & Egypt & 1.169 & 2.510 & 45 & Sierra Leone & 1.067 & 1.046 \\
\hline 17 & El Salvador & 1.223 & 2.164 & 46 & Singapore & 1.945 & 3.358 \\
\hline 18 & Finland & 1.990 & 2.231 & 47 & South Africa & 2.227 & 4.420 \\
\hline 19 & France & 1.573 & 2.782 & 48 & Spain & 2.388 & 4.406 \\
\hline 20 & Ghana & 1.074 & 1.153 & 49 & Sri Lanka & 1.101 & 1.715 \\
\hline 21 & Greece & 1.147 & 2.259 & 50 & Sweden & 2.203 & 3.267 \\
\hline 22 & Guatemala & 1.139 & 1.631 & 51 & Switzerland & 3.220 & 6.168 \\
\hline 23 & Honduras & 1.134 & 1.981 & 52 & Syria & 1.213 & 1.133 \\
\hline 24 & Iceland & 1.730 & 9.489 & 53 & Thailand & 1.153 & 2.808 \\
\hline 25 & India & 1.103 & 1.955 & 54 & $\begin{array}{l}\text { Trinidad and To- } \\
\text { bago }\end{array}$ & 1.115 & 1.858 \\
\hline 26 & Ireland & 1.818 & 5.054 & 55 & United Kingdom & 1.239 & 5.639 \\
\hline 27 & Israel & 1.216 & 2.647 & 56 & United States & 2.609 & 8.569 \\
\hline 28 & Italy & 2.901 & 2.664 & 57 & Uruguay & 1.174 & 1.540 \\
\hline 29 & Jamaica & 1.195 & 1.231 & & & & \\
\hline
\end{tabular}


Table 3: Efficiency indices

\begin{tabular}{|c|c|c|c|c|c|}
\hline \multirow[b]{2}{*}{$\#$} & \multirow[b]{2}{*}{ Country } & \multicolumn{2}{|c|}{ Without Financial Development } & \multicolumn{2}{|c|}{ With Financial Development } \\
\hline & & 1965 & 2005 & 1965 & 2005 \\
\hline 1 & Argentina & 0.65 & 0.55 & 0.69 & 0.58 \\
\hline 2 & Australia & 0.79 & 0.86 & 0.80 & 0.87 \\
\hline 3 & Austria & 0.89 & 0.94 & 0.88 & 0.93 \\
\hline 4 & Belgium & 0.80 & 0.90 & 0.85 & 1.00 \\
\hline 5 & Bolivia & 0.63 & 0.43 & 0.67 & 0.33 \\
\hline 6 & Burundi & 0.85 & 0.28 & 0.84 & 0.23 \\
\hline 7 & Canada & 0.99 & 0.85 & 1.00 & 0.71 \\
\hline 8 & Chile & 0.44 & 0.61 & 0.46 & 0.55 \\
\hline 9 & Colombia & 0.54 & 0.51 & 0.55 & 0.42 \\
\hline 10 & Costa Rica & 1.00 & 0.60 & 0.83 & 0.55 \\
\hline 11 & Cote d'Ivoire & 0.76 & 0.58 & 0.74 & 0.59 \\
\hline 12 & Cyprus & 0.38 & 0.68 & 0.34 & 0.51 \\
\hline 13 & Denmark & 0.86 & 0.85 & 0.78 & 0.75 \\
\hline 14 & Dominican Rep. & 0.75 & 0.62 & 0.79 & 0.62 \\
\hline 15 & Ecuador & 0.38 & 0.40 & 0.39 & 0.40 \\
\hline 16 & Egypt & 0.59 & 0.64 & 0.60 & 0.42 \\
\hline 17 & El Salvador & 0.97 & 0.60 & 0.97 & 0.43 \\
\hline 18 & Finland & 0.66 & 0.84 & 0.65 & 0.96 \\
\hline 19 & France & 0.99 & 0.91 & 1.00 & 0.97 \\
\hline 20 & Ghana & 0.12 & 0.21 & 0.12 & 0.22 \\
\hline 21 & Greece & 0.71 & 0.79 & 0.74 & 0.91 \\
\hline 22 & Guatemala & 0.74 & 0.64 & 0.78 & 0.58 \\
\hline 23 & Honduras & 0.65 & 0.39 & 0.67 & 0.30 \\
\hline 24 & Iceland & 0.92 & 0.89 & 0.93 & 0.80 \\
\hline 25 & India & 0.39 & 0.42 & 0.42 & 0.33 \\
\hline 26 & Ireland & 0.71 & 0.94 & 0.57 & 0.84 \\
\hline 27 & Israel & 0.69 & 0.74 & 0.71 & 0.81 \\
\hline 28 & Italy & 0.81 & 0.90 & 0.81 & 0.95 \\
\hline 29 & Jamaica & 0.66 & 0.44 & 0.67 & 0.45 \\
\hline 30 & Japan & 0.65 & 0.68 & 0.45 & 0.69 \\
\hline 31 & Kenya & 0.45 & 0.34 & 0.47 & 0.28 \\
\hline 32 & Malaysia & 0.52 & 0.51 & 0.54 & 0.44 \\
\hline 33 & Mauritius & 0.36 & 0.45 & 0.36 & 0.43 \\
\hline 34 & Mexico & 0.90 & 0.67 & 0.88 & 0.71 \\
\hline 35 & Morocco & 0.47 & 0.35 & 0.49 & 0.28 \\
\hline 36 & Nepal & 1.00 & 0.24 & 1.00 & 0.21 \\
\hline 37 & Netherlands & 1.00 & 0.87 & 1.00 & 0.74 \\
\hline 38 & New Zealand & 0.89 & 0.75 & 0.86 & 0.65 \\
\hline 39 & Norway & 0.86 & 0.99 & 0.86 & 1.00 \\
\hline 40 & Panama & 0.58 & 0.54 & 0.59 & 0.39 \\
\hline 41 & Paraguay & 0.62 & 0.35 & 0.67 & 0.35 \\
\hline
\end{tabular}


Table 3 (Continued)

\begin{tabular}{llllll}
\hline & & \multicolumn{2}{l}{ Without } & Financial Development & \multicolumn{2}{l}{ With Financial Development } \\
$\#$ & Country & 1965 & 2005 & 1965 & 2005 \\
\hline 42 & Peru & 0.50 & 0.42 & 0.53 & 0.42 \\
43 & Philippines & 0.40 & 0.32 & 0.33 & 0.27 \\
44 & Portugal & 0.68 & 0.61 & 0.54 & 0.55 \\
45 & Sierra Leone & 1.00 & 0.50 & 1.00 & 0.52 \\
46 & Singapore & 0.56 & 1.00 & 0.49 & 1.00 \\
47 & South Africa & 0.65 & 0.53 & 0.50 & 0.38 \\
48 & Spain & 0.92 & 0.78 & 0.88 & 0.72 \\
49 & Sri Lanka & 0.22 & 0.35 & 0.23 & 0.29 \\
50 & Sweden & 0.84 & 0.87 & 0.82 & 0.88 \\
51 & Switzerland & 0.97 & 0.79 & 0.97 & 0.74 \\
52 & Syria & 1.00 & 0.64 & 1.00 & 0.67 \\
53 & Thailand & 0.32 & 0.37 & 0.33 & 0.31 \\
54 & Trinidad and To- & 0.72 & 0.80 & 0.77 & 0.88 \\
& bago & & & \\
55 & United Kingdom & 1.00 & 1.00 & 1.00 & 0.88 \\
56 & United States & 1.00 & 0.95 & 0.95 & 0.82 \\
57 & Uruguay & 0.53 & 0.58 & 0.55 & 0.51 \\
\hline & Average & 0.70 & 0.64 & 0.69 & 0.60 \\
\hline
\end{tabular}


Table 4: Percentage change of quinquepartite decomposition indices, 1965-2005

\begin{tabular}{|c|c|c|c|c|c|c|c|}
\hline$\#$ & Country & $\begin{array}{l}\text { (PROD- } \\
1) \times 100\end{array}$ & $\begin{array}{r}(\mathrm{EFF}- \\
1) \times 100\end{array}$ & $\begin{array}{l}(\mathrm{TECH}- \\
1) \times 100\end{array}$ & $\begin{array}{l}(\mathrm{KACC}- \\
1) \times 100\end{array}$ & $\begin{array}{l}(\mathrm{HACC}- \\
1) \times 100\end{array}$ & $\begin{array}{r}\text { (FKACC- } \\
\times 100\end{array}$ \\
\hline \multirow[t]{2}{*}{1} & Argentina & 19.2 & -15.6 & 0.0 & 24.5 & 13.4 & 0.0 \\
\hline & & 19.2 & -14.7 & 0.0 & 22.3 & 14.2 & \\
\hline \multirow[t]{2}{*}{2} & Australia & 103.2 & 8.5 & 22.4 & 21.5 & 13.8 & 10.6 \\
\hline & & 103.2 & 8.9 & 25.2 & 33.1 & 11.9 & \\
\hline \multirow[t]{2}{*}{3} & Austria & 155.3 & 5.4 & 31.3 & 26.2 & 39.0 & 5.2 \\
\hline & & 155.3 & 5.1 & 29.9 & 43.4 & 30.4 & \\
\hline \multirow[t]{2}{*}{4} & Belgium & 138.6 & 17.7 & 22.1 & 24.2 & 24.4 & 7.3 \\
\hline & & 138.6 & 12.0 & 33.5 & 32.9 & 20.1 & \\
\hline \multirow[t]{2}{*}{5} & Bolivia & -9.7 & -50.5 & 0.0 & -2.4 & 29.8 & 43.9 \\
\hline & & -9.7 & -30.9 & 0.0 & -3.4 & 35.4 & \\
\hline \multirow[t]{2}{*}{6} & Burundi & 38.4 & -72.2 & 0.0 & 244.2 & 6.4 & 35.9 \\
\hline & & 38.4 & -67.3 & 0.0 & 297.1 & 6.7 & \\
\hline \multirow[t]{2}{*}{7} & Canada & 60.4 & -29.5 & 32.9 & 19.3 & 13.9 & 26.0 \\
\hline & & 60.4 & -14.4 & 21.5 & 35.9 & 13.5 & \\
\hline \multirow[t]{2}{*}{8} & Chile & 117.3 & 18.0 & 1.9 & 14.2 & 25.6 & 26.0 \\
\hline & & 117.3 & 40.9 & 0.0 & 27.2 & 21.3 & \\
\hline \multirow[t]{2}{*}{9} & Colombia & 66.5 & -22.6 & 0.0 & 51.2 & 24.4 & 14.4 \\
\hline & & 66.5 & -6.0 & 0.0 & 49.3 & 18.7 & \\
\hline \multirow[t]{2}{*}{10} & Costa Rica & 29.5 & -34.2 & 0.5 & 48.0 & 29.6 & 2.0 \\
\hline & & 29.5 & -39.8 & 0.0 & 72.2 & 24.8 & \\
\hline \multirow[t]{2}{*}{11} & Cote d'Ivoire & 20.8 & -19.9 & 0.0 & 42.5 & 10.2 & -4.0 \\
\hline & & 20.8 & -23.6 & 0.0 & 45.0 & 8.9 & \\
\hline \multirow[t]{2}{*}{12} & Cyprus & 240.5 & 49.9 & 25.0 & 18.9 & 36.4 & 12.1 \\
\hline & & 240.5 & 77.6 & 7.6 & 40.3 & 27.0 & \\
\hline \multirow[t]{2}{*}{13} & Denmark & 104.1 & -3.7 & 33.2 & 23.7 & 10.7 & 16.2 \\
\hline & & 104.1 & -1.1 & 24.3 & 52.7 & 8.7 & \\
\hline \multirow[t]{2}{*}{14} & Dominican Rep. & 110.1 & -21.1 & 0.0 & 105.1 & 20.2 & 8.0 \\
\hline & & 110.1 & -18.0 & 0.0 & 108.9 & 22.6 & \\
\hline \multirow[t]{2}{*}{15} & Ecuador & 50.5 & 2.4 & 0.0 & 20.6 & 20.0 & 1.5 \\
\hline & & 50.5 & 4.7 & 0.0 & 20.9 & 18.9 & \\
\hline \multirow[t]{2}{*}{16} & Egypt & 195.2 & -29.9 & 0.0 & 108.2 & 41.7 & 42.6 \\
\hline & & 195.2 & 7.6 & 0.0 & 122.1 & 23.5 & \\
\hline \multirow[t]{2}{*}{17} & El Salvador & 19.7 & -56.1 & 0.0 & 55.3 & 43.9 & 22.1 \\
\hline & & 19.7 & -38.7 & 0.0 & 50.9 & 29.4 & \\
\hline \multirow[t]{2}{*}{18} & Finland & 171.7 & 47.0 & 18.2 & 18.3 & 30.9 & 1.0 \\
\hline & & 171.7 & 26.1 & 26.0 & 37.7 & 24.2 & \\
\hline \multirow[t]{2}{*}{19} & France & 130.6 & -3.2 & 21.4 & 21.9 & 52.7 & 5.4 \\
\hline & & 130.6 & -8.0 & 27.6 & 39.6 & 40.8 & \\
\hline \multirow[t]{2}{*}{20} & Ghana & 71.9 & 74.1 & 0.0 & -25.6 & 27.2 & 4.3 \\
\hline & & 71.9 & 80.6 & 0.0 & -25.9 & 28.5 & \\
\hline \multirow[t]{2}{*}{21} & Greece & 163.3 & 22.9 & 14.4 & 30.7 & 22.2 & 17.3 \\
\hline & & & & & & I & oage) \\
\hline
\end{tabular}


Table 4 (Continued)

\begin{tabular}{|c|c|c|c|c|c|c|c|}
\hline$\#$ & Country & $\begin{array}{l}(\text { PROD- } \\
1) \times 100\end{array}$ & $\begin{array}{r}(\mathrm{EFF}- \\
1) \times 100\end{array}$ & $\begin{array}{l}(\mathrm{TECH}- \\
1) \times 100\end{array}$ & $\begin{array}{l}(\mathrm{KACC}- \\
1) \times 100\end{array}$ & $\begin{array}{l}(\mathrm{HACC}- \\
1) \times 100\end{array}$ & $\begin{array}{r}(\text { FKACC- } \\
\times 100\end{array}$ \\
\hline & & 163.3 & 11.5 & 22.7 & 57.0 & 22.5 & \\
\hline \multirow[t]{2}{*}{22} & Guatemala & 58.0 & -25.9 & 0.2 & 51.6 & 24.8 & 12.4 \\
\hline & & 58.0 & -13.8 & 0.0 & 54.9 & 18.3 & \\
\hline \multirow[t]{2}{*}{23} & Honduras & 28.9 & -56.0 & 0.0 & 69.7 & 41.2 & 22.3 \\
\hline & & 28.9 & -39.1 & 0.0 & 63.4 & 29.5 & \\
\hline \multirow[t]{2}{*}{24} & Iceland & 104.5 & -14.2 & 38.3 & 3.6 & 29.4 & 28.4 \\
\hline & & 104.5 & -3.6 & 40.2 & 23.4 & 22.6 & \\
\hline \multirow[t]{2}{*}{25} & India & 220.8 & -20.7 & 0.0 & 139.0 & 16.1 & 45.7 \\
\hline & & 220.8 & 8.3 & 0.0 & 154.3 & 16.4 & \\
\hline \multirow[t]{2}{*}{26} & Ireland & 252.7 & 48.5 & 28.7 & 37.5 & 15.7 & 16.0 \\
\hline & & 252.7 & 32.1 & 22.0 & 91.0 & 14.6 & \\
\hline \multirow[t]{2}{*}{27} & Israel & 107.1 & 14.5 & 16.5 & 18.2 & 20.8 & 8.8 \\
\hline & & 107.1 & 7.1 & 24.7 & 31.7 & 17.8 & \\
\hline \multirow[t]{2}{*}{28} & Italy & 162.5 & 17.6 & 35.5 & 22.2 & 36.1 & -1.0 \\
\hline & & 162.5 & 11.7 & 34.8 & 34.5 & 29.7 & \\
\hline \multirow[t]{2}{*}{29} & Jamaica & 22.3 & -33.1 & 0.0 & 33.5 & 35.5 & 1.0 \\
\hline & & 22.3 & -33.1 & 0.4 & 35.8 & 34.1 & \\
\hline \multirow[t]{2}{*}{30} & Japan & 236.5 & 53.4 & 26.4 & 36.5 & 20.0 & 5.9 \\
\hline & & 236.5 & 5.2 & 26.9 & 112.6 & 18.5 & \\
\hline \multirow[t]{2}{*}{31} & Kenya & 3.3 & -40.9 & 0.0 & 18.5 & 17.6 & 25.5 \\
\hline & & 3.3 & -25.4 & 0.0 & 18.7 & 16.8 & \\
\hline \multirow[t]{2}{*}{32} & Malaysia & 357.9 & -19.0 & 8.0 & 154.9 & 44.4 & 42.2 \\
\hline & & 357.9 & -2.5 & 2.2 & 224.1 & 41.8 & \\
\hline \multirow[t]{2}{*}{33} & Mauritius & 157.3 & 21.8 & 3.4 & 35.6 & 23.5 & 21.9 \\
\hline & & 157.3 & 26.6 & 2.3 & 62.9 & 22.1 & \\
\hline \multirow[t]{2}{*}{34} & Mexico & 37.5 & -18.9 & 0.6 & 22.9 & 52.7 & -10.2 \\
\hline & & 37.5 & -25.2 & 1.6 & 26.3 & 43.3 & \\
\hline \multirow[t]{2}{*}{35} & Morocco & 101.8 & -41.9 & 1.0 & 93.5 & 43.2 & 24.1 \\
\hline & & 101.8 & -25.7 & 0.0 & 104.7 & 32.7 & \\
\hline \multirow[t]{2}{*}{36} & Nepal & 62.9 & -79.1 & 0.0 & 384.8 & 10.9 & 45.1 \\
\hline & & 62.9 & -75.6 & 0.0 & 491.0 & 12.9 & \\
\hline \multirow[t]{2}{*}{37} & Netherlands & 68.8 & -26.0 & 39.4 & 12.5 & 25.5 & 15.8 \\
\hline & & 68.8 & -12.8 & 28.1 & 25.2 & 20.7 & \\
\hline \multirow[t]{2}{*}{38} & New Zealand & 24.1 & -24.6 & 17.5 & 12.5 & 12.1 & 11.0 \\
\hline & & 24.1 & -15.1 & 8.8 & 22.8 & 9.4 & \\
\hline \multirow[t]{2}{*}{39} & Norway & 151.1 & 16.9 & 44.6 & 16.5 & 27.7 & -0.2 \\
\hline & & 151.1 & 16.0 & 43.8 & 22.6 & 22.8 & \\
\hline \multirow[t]{2}{*}{40} & Panama & 106.2 & -33.8 & 0.2 & 81.6 & 35.5 & 26.3 \\
\hline & & 106.2 & -5.8 & 0.0 & 79.0 & 22.3 & \\
\hline \multirow[t]{2}{*}{41} & Paraguay & 39.8 & -47.6 & 0.0 & 117.7 & 15.8 & 5.9 \\
\hline & & 39.8 & -44.2 & 0.0 & 119.2 & 14.4 & \\
\hline \multirow[t]{2}{*}{42} & Peru & -17.5 & -20.7 & 0.4 & -20.5 & 26.2 & 3.3 \\
\hline & \multicolumn{7}{|c|}{ (continued on next page) } \\
\hline
\end{tabular}


Table 4 (Continued)

\begin{tabular}{|c|c|c|c|c|c|c|c|}
\hline$\#$ & Country & $\begin{array}{l}\text { (PROD- } \\
1) \times 100\end{array}$ & $\begin{array}{r}(\mathrm{EFF}- \\
\text { 1) } \times 100\end{array}$ & $\begin{array}{l}(\mathrm{TECH}- \\
1) \times 100\end{array}$ & $\begin{array}{l}\text { (KACC- } \\
1) \times 100\end{array}$ & $\begin{array}{l}\text { (HACC- } \\
1) \times 100\end{array}$ & $\begin{array}{r}(\text { FKACC- } \\
\times 100\end{array}$ \\
\hline & & -17.5 & -17.3 & 4.1 & -20.9 & 21.2 & \\
\hline \multirow[t]{2}{*}{43} & Philippines & 45.7 & -19.7 & 0.0 & 45.5 & 13.5 & 9.8 \\
\hline & & 45.7 & -21.7 & 0.0 & 62.0 & 14.9 & \\
\hline \multirow[t]{2}{*}{44} & Portugal & 172.5 & 2.3 & 29.8 & 30.6 & 47.5 & 6.5 \\
\hline & & 172.5 & -10.4 & 22.3 & 84.6 & 34.8 & \\
\hline \multirow[t]{2}{*}{45} & Sierra Leone & -3.7 & -47.5 & 0.0 & 59.0 & 16.6 & -1.0 \\
\hline & & -3.7 & -50.1 & 0.0 & 68.7 & 14.5 & \\
\hline \multirow[t]{2}{*}{46} & Singapore & 476.4 & 104.8 & 33.5 & 39.2 & 40.0 & 8.1 \\
\hline & & 476.4 & 77.1 & 32.9 & 85.5 & 32.0 & \\
\hline \multirow[t]{2}{*}{47} & South Africa & 34.4 & -23.4 & 6.7 & 9.6 & 35.3 & 10.9 \\
\hline & & 34.4 & -18.4 & 0.0 & 37.7 & 19.6 & \\
\hline \multirow[t]{2}{*}{48} & Spain & 142.4 & -18.2 & 32.2 & 26.3 & 67.8 & 5.8 \\
\hline & & 142.4 & -15.2 & 24.5 & 53.2 & 49.9 & \\
\hline \multirow[t]{2}{*}{49} & Sri Lanka & 233.5 & 23.7 & 0.0 & 80.3 & 10.4 & 35.5 \\
\hline & & 233.5 & 58.8 & 0.0 & 89.4 & 10.9 & \\
\hline \multirow[t]{2}{*}{50} & Sweden & 100.8 & 7.0 & 21.5 & 15.6 & 28.2 & 4.2 \\
\hline & & 100.8 & 2.6 & 21.2 & 32.1 & 22.3 & \\
\hline \multirow[t]{2}{*}{51} & Switzerland & 49.0 & -23.9 & 51.8 & 6.2 & 9.0 & 11.4 \\
\hline & & 49.0 & -18.5 & 43.7 & 18.4 & 7.4 & \\
\hline \multirow[t]{2}{*}{52} & Syria & 48.1 & -33.0 & 0.0 & 107.4 & 11.9 & -4.8 \\
\hline & & 48.1 & -36.2 & 0.0 & 109.4 & 10.8 & \\
\hline \multirow[t]{2}{*}{53} & Thailand & 401.5 & -7.2 & 2.7 & 203.3 & 20.6 & 43.9 \\
\hline & & 401.5 & 15.3 & 0.0 & 281.3 & 14.1 & \\
\hline \multirow[t]{2}{*}{54} & Trinidad and To- & 99.2 & 15.4 & 4.1 & 16.6 & 22.4 & 16.3 \\
\hline & & 99.2 & 11.1 & 8.8 & 33.5 & 23.4 & \\
\hline \multirow[t]{2}{*}{55} & United Kingdom & 127.5 & -12.1 & 29.3 & 37.4 & 14.4 & 27.3 \\
\hline & & 127.5 & 0.0 & 21.2 & 64.1 & 14.4 & \\
\hline \multirow[t]{2}{*}{56} & United States & 79.4 & -13.2 & 37.3 & 11.2 & 13.4 & 19.4 \\
\hline & & 79.4 & -5.2 & 23.8 & 38.0 & 10.7 & \\
\hline \multirow[t]{4}{*}{57} & Uruguay & 77.2 & -7.2 & 0.0 & 44.7 & 16.5 & 13.2 \\
\hline & & 77.2 & 7.9 & 0.0 & 44.9 & 13.3 & \\
\hline & Average & 111.7 & -8.7 & 12.9 & 52.0 & 25.9 & 15.0 \\
\hline & & 111.7 & -3.9 & 11.5 & 70.9 & 21.5 & \\
\hline
\end{tabular}


Table 5: Mean percentage changes of quinquepartite decomposition indices (country groupings)

\begin{tabular}{lrrrrrrrr}
\hline \multirow{2}{*}{ Country group } & $\mathrm{TE}_{b}$ & $\mathrm{TE}_{c}$ & 1) $\times 100$ & 1) $\times 100$ & $1) \times 100$ & $1) \times 100$ & $1) \times 100$ & $\times 100$ \\
\hline OECD $^{*}$ & 0.83 & 0.82 & 124.4 & 2.7 & 28.6 & 21.7 & 27.6 & 10.4 \\
Asian Tigers** & 0.45 & 0.61 & 368.1 & 33.0 & 17.6 & 108.5 & 31.3 & 25.0 \\
Latin America & 0.66 & 0.48 & 51.1 & -24.3 & 0.5 & 44.5 & 26.5 & 13.7 \\
Africa & 0.57 & 0.37 & 68.8 & -20.0 & 1.2 & 65.1 & 24.6 & 17.8 \\
Non-OECD & 0.60 & 0.46 & 103.7 & -15.8 & 3.0 & 71.1 & 24.9 & 17.9 \\
ALL & 0.69 & 0.60 & 111.7 & -8.7 & 12.9 & 52.0 & 25.9 & 15.0 \\
\hline
\end{tabular}

* OECD countries as of 1990.

** Japan, Malaysia, Singapore, and Thailand. 
Table 6: Modality tests ( $p$-values)

\begin{tabular}{rlc}
\hline & $H_{0}:$ Distribution has one mode & Bootstrap \\
& $H_{A}:$ Distribution has more than one mode & $p$-value \\
\hline 1 & $f\left(y_{2005}\right)$ & 0.0000 \\
2 & $f\left(y_{1965}\right)$ & 0.7407 \\
3 & $f\left(y_{1965} \times E F F\right)$ & 0.0000 \\
4 & $f\left(y_{1965} \times T E C H\right)$ & 0.3694 \\
5 & $f\left(y_{1965} \times K A C C\right)$ & 0.6527 \\
6 & $f\left(y_{1965} \times H A C C\right)$ & 0.0761 \\
7 & $f\left(y_{1965} \times F K A C C\right)$ & 0.8899 \\
8 & $f\left(y_{1965} \times E F F \times T E C H\right)$ & 0.0000 \\
9 & $f\left(y_{1965} \times E F F \times K A C C\right)$ & 0.0000 \\
10 & $f\left(y_{1965} \times E F F \times H A C C\right)$ & 0.0000 \\
11 & $f\left(y_{1965} \times E F F \times F K A C C\right)$ & 0.0000 \\
12 & $f\left(y_{1965} \times T E C H \times K A C C\right)$ & 0.2052 \\
13 & $f\left(y_{1965} \times T E C H \times H A C C\right)$ & 0.0951 \\
14 & $f\left(y_{1965} \times T E C H \times F K A C C\right)$ & 0.6887 \\
15 & $f\left(y_{1965} \times K A C C \times H A C C\right)$ & 0.0390 \\
16 & $f\left(y_{1965} \times K A C C \times F K A C C\right)$ & 0.8889 \\
17 & $f\left(y_{1965} \times H A C C \times F K A C C\right)$ & 0.1742 \\
18 & $f\left(y_{1965} \times E F F \times T E C H \times K A C C\right)$ & 0.0000 \\
19 & $f\left(y_{1965} \times E F F \times T E C H \times H A C C\right)$ & 0.0010 \\
20 & $f\left(y_{1965} \times E F F \times T E C H \times F K A C C\right)$ & 0.0000 \\
21 & $f\left(y_{1965} \times E F F \times K A C C \times H A C C\right)$ & 0.0000 \\
22 & $f\left(y_{1965} \times E F F \times K A C C \times F K A C C\right)$ & 0.0000 \\
23 & $f\left(y_{1965} \times E F F \times H A C C \times F K A C C\right)$ & 0.0000 \\
24 & $f\left(y_{1965} \times T E C H \times K A C C \times H A C C\right)$ & 0.0340 \\
25 & $f\left(y_{1965} \times T E C H \times K A C C \times F K A C C\right)$ & 0.6196 \\
26 & $f\left(y_{1965} \times T E C H \times H A C C \times F K A C C\right)$ & 0.1341 \\
27 & $f\left(y_{1965} \times K A C C \times H A C C \times F K A C C\right)$ & 0.0991 \\
28 & $f\left(y_{1965} \times E F F \times T E C H \times K A C C \times H A C C\right)$ & 0.0000 \\
29 & $f\left(y_{1965} \times E F F \times T E C H \times K A C C \times F K A C C\right)$ & 0.0000 \\
30 & $f\left(y_{1965} \times E F F \times T E C H \times H A C C \times F K A C C\right)$ & 0.0000 \\
31 & $f\left(y_{1965} \times E F F \times K A C C \times H A C C \times F K A C C\right)$ & 0.0000 \\
32 & $f\left(y_{1965} \times T E C H \times K A C C \times H A C C \times F K A C C\right)$ & 0.0661 \\
\hline & $N o t e s:$ & $1+5$ \\
\hline
\end{tabular}

Notes: We used the bootstrapped calibrated Silverman test for multimodality due to Hall and York (2001) with 1000 bootstrap replications. 
Table 7: Distribution hypothesis tests ( $p$-values)

\begin{tabular}{|c|c|c|}
\hline & $\begin{array}{l}\mathrm{H}_{0} \text { : Distributions are equal } \\
\mathrm{H}_{1} \text { : Distributions are not equal }\end{array}$ & $\begin{array}{l}\text { Bootstrap } \\
\text { p-value }\end{array}$ \\
\hline 1 & $g\left(y_{2005}\right)$ vs. $f\left(y_{1965}\right)$ & 0.0014 \\
\hline 2 & $g\left(y_{2005}\right)$ vs. $f\left(y_{1965} \times E F F\right)$ & 0.0000 \\
\hline 3 & $g\left(y_{2005}\right)$ vs. $f\left(y_{1965} \times T E C H\right)$ & 0.0042 \\
\hline 4 & $g\left(y_{2005}\right)$ vs. $f\left(y_{1965} \times K A C C\right)$ & 0.0004 \\
\hline 5 & $g\left(y_{2005}\right)$ vs. $f\left(y_{1965} \times H A C C\right)$ & 0.0004 \\
\hline 6 & $g\left(y_{2005}\right)$ vs. $f\left(y_{1965} \times F K A C C\right)$ & 0.0018 \\
\hline 7 & $g\left(y_{2005}\right)$ vs. $f\left(y_{1965} \times E F F \times T E C H\right)$ & 0.0000 \\
\hline 8 & $g\left(y_{2005}\right)$ vs. $f\left(y_{1965} \times E F F \times K A C C\right)$ & 0.0004 \\
\hline 9 & $g\left(y_{2005}\right)$ vs. $f\left(y_{1965} \times E F F \times H A C C\right)$ & 0.0000 \\
\hline 10 & $g\left(y_{2005}\right)$ vs. $f\left(y_{1965} \times E F F \times F K A C C\right)$ & 0.0000 \\
\hline 11 & $g\left(y_{2005}\right)$ vs. $f\left(y_{1965} \times T E C H \times K A C C\right)$ & 0.0364 \\
\hline 12 & $g\left(y_{2005}\right)$ vs. $f\left(y_{1965} \times T E C H \times H A C C\right)$ & 0.0424 \\
\hline 13 & $g\left(y_{2005}\right)$ vs. $f\left(y_{1965} \times T E C H \times F K A C C\right)$ & 0.0288 \\
\hline 14 & $g\left(y_{2005}\right)$ vs. $f\left(y_{1965} \times K A C C \times H A C C\right)$ & 0.0006 \\
\hline 15 & $g\left(y_{2005}\right)$ vs. $f\left(y_{1965} \times K A C C \times F K A C C\right)$ & 0.0020 \\
\hline 16 & $g\left(y_{2005}\right)$ vs. $f\left(y_{1965} \times H A C C \times F K A C C\right)$ & 0.0036 \\
\hline 17 & $g\left(y_{2005}\right)$ vs. $f\left(y_{1965} \times E F F \times T E C H \times K A C C\right)$ & 0.0018 \\
\hline 18 & $g\left(y_{2005}\right)$ vs. $f\left(y_{1965} \times E F F \times T E C H \times H A C C\right)$ & 0.0006 \\
\hline 19 & $g\left(y_{2005}\right)$ vs. $f\left(y_{1965} \times E F F \times T E C H \times F K A C C\right)$ & 0.0000 \\
\hline 20 & $g\left(y_{2005}\right)$ vs. $f\left(y_{1965} \times E F F \times K A C C \times H A C C\right)$ & 0.0008 \\
\hline 21 & $g\left(y_{2005}\right)$ vs. $f\left(y_{1965} \times E F F \times K A C C \times F K A C C\right)$ & 0.0000 \\
\hline 22 & $g\left(y_{2005}\right)$ vs. $f\left(y_{1965} \times E F F \times H A C C \times F K A C C\right)$ & 0.0002 \\
\hline 23 & $g\left(y_{2005}\right)$ vs. $f\left(y_{1965} \times T E C H \times K A C C \times H A C C\right)$ & 0.5812 \\
\hline 24 & $g\left(y_{2005}\right)$ vs. $f\left(y_{1965} \times T E C H \times K A C C \times F K A C C\right)$ & 0.0580 \\
\hline 25 & $g\left(y_{2005}\right)$ vs. $f\left(y_{1965} \times T E C H \times H A C C \times F K A C C\right)$ & 0.0556 \\
\hline 26 & $g\left(y_{2005}\right)$ vs. $f\left(y_{1965} \times K A C C \times H A C C \times F K A C C\right)$ & 0.0062 \\
\hline 27 & $g\left(y_{2005}\right)$ vs. $f\left(y_{1965} \times E F F \times T E C H \times K A C C \times H A C C\right)$ & 0.2990 \\
\hline 28 & $g\left(y_{2005}\right)$ vs. $f\left(y_{1965} \times E F F \times T E C H \times K A C C \times F K A C C\right)$ & 0.0222 \\
\hline 29 & $g\left(y_{2005}\right)$ vs. $f\left(y_{1965} \times E F F \times T E C H \times H A C C \times F K A C C\right)$ & 0.0064 \\
\hline 30 & $g\left(y_{2005}\right)$ vs. $f\left(y_{1965} \times E F F \times K A C C \times H A C C \times F K A C C\right)$ & 0.0030 \\
\hline 31 & $g\left(y_{2005}\right)$ vs. $f\left(y_{1965} \times T E C H \times K A C C \times H A C C \times F K A C C\right)$ & 0.0870 \\
\hline
\end{tabular}

Notes: We used the bootstrapped Li (1996) test with 5000 bootstrap replications and the Sheather and Jones (1991) bandwidth. 
Table 8: Mean efficiency scores and percentage change of quintipartite decomposition indices, 1965-2005

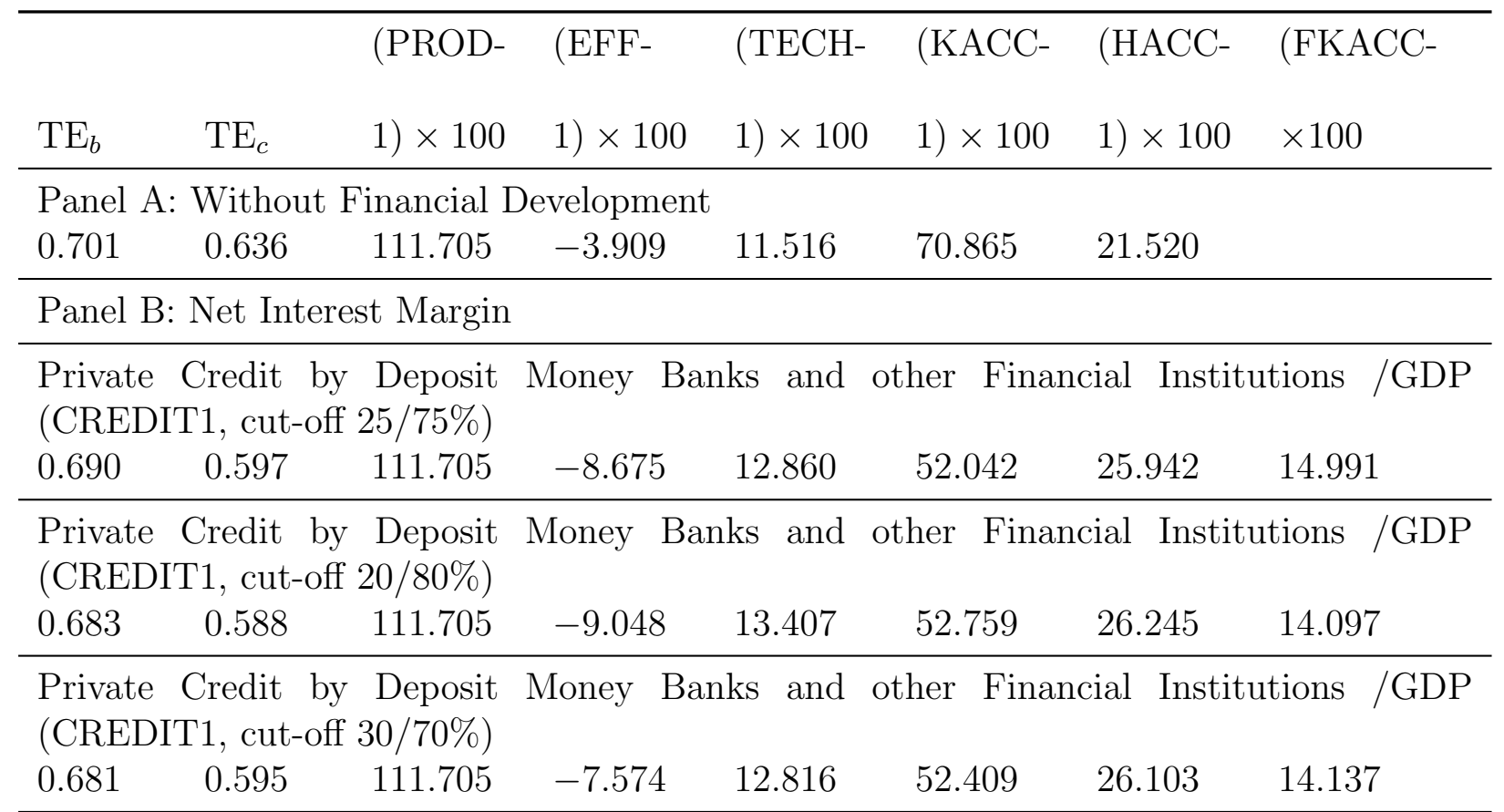

Private Credit by Deposit Money Banks/GDP (CREDIT2, cut-off 25/75\%)

$\begin{array}{llllllll}0.684 & 0.585 & 111.705 & -9.392 & 13.860 & 54.299 & 25.424 & 13.494\end{array}$

Liquid Liabilities/GDP (LLY, cut-off 25/75\%)

$\begin{array}{llllllll}0.714 & 0.606 & 109.405 & -10.863 & 13.515 & 54.240 & 24.338 & 15.363\end{array}$

Claims on the Non-financial Private Sector/ GDP (PRIVY, cut-off 25/75\%)

$\begin{array}{llllllll}0.714 & 0.611 & 111.705 & -10.428 & 12.516 & 51.406 & 24.833 & 16.181\end{array}$

Panel C: Overhead Costs

Private Credit by Deposit Money Banks and other Financial Institutions /GDP (CREDIT1, cut-off 25/75\%)

$\begin{array}{llllllll}0.680 & 0.584 & 111.705 & -9.376 & 13.578 & 50.093 & 27.233 & 17.098\end{array}$

Private Credit by Deposit Money Banks and other Financial Institutions /GDP (CREDIT1, cut-off 20/80\%)

$\begin{array}{llllllll}0.669 & 0.575 & 111.705 & -8.990 & 14.032 & 50.884 & 27.735 & 15.876\end{array}$

Private Credit by Deposit Money Banks and other Financial Institutions /GDP (CREDIT1, cut-off 30/70\%)

$\begin{array}{llllllll}0.680 & 0.586 & 111.705 & -8.959 & 13.680 & 49.993 & 26.856 & 17.342\end{array}$

Private Credit by Deposit Money Banks/GDP (CREDIT2, cut-off 25/75\%)

$\begin{array}{llllllll}0.669 & 0.574 & 111.705 & -8.953 & 14.298 & 53.395 & 26.739 & 14.126\end{array}$

Liquid Liabilities/GDP (LLY, cut-off 25/75\%)

$\begin{array}{llllllll}0.715 & 0.604 & 109.405 & -11.442 & 13.423 & 51.018 & 25.454 & 17.542\end{array}$

Claims on the Non-financial Private Sector/ GDP (PRIVY, cut-off 25/75\%) 
Table 8 (Continued)

\begin{tabular}{|c|c|c|c|c|c|c|c|}
\hline $\mathrm{TE}_{b}$ & $\mathrm{TE}_{c}$ & (PROD- & 1) $\times 100$ & (TECH- & $(\mathrm{KACC}-$ & (HACC- & (FKACC- \\
\hline 0.700 & 0.600 & 111.705 & -10.149 & 12.944 & 50.325 & 25.458 & 17.077 \\
\hline \multicolumn{8}{|c|}{$\begin{array}{l}\text { Panel D: HR Time Period: 1965-1990, Net Interest Margin } \\
\text { Without Financial Development }\end{array}$} \\
\hline \multicolumn{8}{|c|}{$\begin{array}{l}\text { Private Credit by Deposit Money Banks and other Financial Institutions /GDP } \\
\text { (CREDIT1, cut-off } 25 / 75 \%)\end{array}$} \\
\hline \multicolumn{8}{|c|}{ Private Credit by Deposit Money Banks/GDP (CREDIT2, cut-off 25/75\%) } \\
\hline \multicolumn{7}{|c|}{ Liquid Liabilities/GDP (LLY, cut-off 25/75\%) } & 7.602 \\
\hline \multicolumn{8}{|c|}{ Claims on the Non-financial Private Sector/ GDP (PRIVY, cut-off 25/75\%) } \\
\hline
\end{tabular}


Table 9: Percentage contributions of the productivity components, 1965-2005

\begin{tabular}{|c|c|c|c|c|}
\hline $\begin{array}{l}\text { Efficiency } \\
\text { change }\end{array}$ & $\begin{array}{l}\text { Technological } \\
\text { change }\end{array}$ & $\begin{array}{l}\text { Physical capital } \\
\text { accumulation }\end{array}$ & $\begin{array}{l}\text { Human capital } \\
\text { accumulation }\end{array}$ & $\begin{array}{l}\text { Financial } \\
\text { development }\end{array}$ \\
\hline \multicolumn{5}{|c|}{ Panel A: Without Financial Development } \\
\hline-14.674 & 15.397 & 70.148 & \multicolumn{2}{|l|}{29.129} \\
\hline \multicolumn{5}{|c|}{ Panel B: Net Interest Margin } \\
\hline \multirow{2}{*}{\multicolumn{5}{|c|}{$\begin{array}{l}\text { Private Credit by Deposit } \\
\text { (CREDIT1, cut-off } 25 / 75 \%) \\
-25.218\end{array}$}} \\
\hline & & & & \\
\hline \multicolumn{5}{|c|}{$\begin{array}{l}\text { Private Credit by Deposit Money Banks and other Financial Institutions /GDP } \\
\text { (CREDIT1, cut-off } 20 / 80 \% \text { ) }\end{array}$} \\
\hline-25.603 & 17.764 & 54.313 & 34.559 & 18.967 \\
\hline \multirow{2}{*}{\multicolumn{5}{|c|}{$\begin{array}{l}\text { Private Credit by Deposit Money Banks and other Financial Institutions /GDP } \\
\text { (CREDIT1, cut-off } 30 / 70 \%)\end{array}$}} \\
\hline & & & & \\
\hline \multicolumn{5}{|c|}{ Private Credit by Deposit Money Banks/GDP (CREDIT2, cut-off 25/75\%) } \\
\hline-25.642 & 18.282 & 55.360 & 33.652 & 18.348 \\
\hline \multicolumn{5}{|c|}{ Liquid Liabilities/GDP (LLY, cut-off 25/75\%) } \\
\hline-29.279 & 18.104 & 57.634 & 33.020 & 20.521 \\
\hline \multicolumn{5}{|c|}{ Claims on the Non-financial Private Sector/ GDP (PRIVY, cut-off 25/75\%) } \\
\hline-26.270 & 16.631 & 54.608 & 33.096 & 21.936 \\
\hline \multicolumn{5}{|c|}{ Panel C: Overhead Costs } \\
\hline \multirow{2}{*}{\multicolumn{5}{|c|}{$\begin{array}{l}\text { Private Credit by Deposit Money Banks and other Financial Institutions /GDP } \\
\text { (CREDIT1, cut-off 25/75\%) } \\
\text { C. }\end{array}$}} \\
\hline & & & & \\
\hline \multicolumn{5}{|c|}{$\begin{array}{l}\text { Private Credit by Deposit Money Banks and other Financial Institutions /GDP } \\
\text { (CREDIT1, cut-off } 20 / 80 \% \text { ) }\end{array}$} \\
\hline-27.032 & 18.558 & 51.481 & 36.221 & 20.772 \\
\hline \multicolumn{5}{|c|}{$\begin{array}{l}\text { Private Credit by Deposit Money Banks and other Financial Institutions /GDP } \\
\text { (CREDIT1, cut-off } 30 / 70 \% \text { ) }\end{array}$} \\
\hline-26.712 & 18.051 & 50.963 & 35.203 & 22.494 \\
\hline \multicolumn{5}{|c|}{ Private Credit by Deposit Money Banks/GDP (CREDIT2, cut-off 25/75\%) } \\
\hline-25.964 & 18.845 & 53.235 & 35.099 & 18.785 \\
\hline \multicolumn{5}{|c|}{ Liquid Liabilities/GDP (LLY, cut-off 25/75\%) } \\
\hline-30.408 & 18.004 & 54.845 & 34.371 & 23.188 \\
\hline \multicolumn{5}{|c|}{ Claims on the Non-financial Private Sector/ GDP (PRIVY, cut-off 25/75\%) } \\
\hline-26.792 & 17.198 & 52.753 & & 23.065 \\
\hline
\end{tabular}


Table 9 (Continued)

\begin{tabular}{|c|c|c|c|c|}
\hline $\begin{array}{l}\text { Efficiency } \\
\text { change }\end{array}$ & $\begin{array}{l}\text { Technological } \\
\text { change }\end{array}$ & $\begin{array}{l}\text { Physical capital } \\
\text { accumulation }\end{array}$ & $\begin{array}{l}\text { Human capital } \\
\text { accumulation }\end{array}$ & $\begin{array}{l}\text { Financial } \\
\text { development }\end{array}$ \\
\hline \multicolumn{5}{|c|}{$\begin{array}{l}\text { Panel D: HR Time Period: 1965-1990, Net Interest Margin } \\
\text { Without Financial Development }\end{array}$} \\
\hline-26.907 & 13.357 & 84.151 & 29.399 & \\
\hline \multicolumn{5}{|c|}{$\begin{array}{l}\text { Private Credit by Deposit Money Banks and other Financial Institutions /GDP } \\
\text { (CREDIT1, cut-off } 25 / 75 \% \text { ) }\end{array}$} \\
\hline-36.030 & 15.890 & 67.873 & 33.813 & 18.455 \\
\hline \multicolumn{5}{|c|}{ Private Credit by Deposit Money Banks/GDP (CREDIT2, cut-off 25/75\%) } \\
\hline-30.391 & 12.866 & 68.733 & 33.610 & 15.183 \\
\hline \multicolumn{5}{|c|}{ Liquid Liabilities/GDP (LLY, cut-off $25 / 75 \%$ ) } \\
\hline-32.068 & 15.402 & 68.376 & 33.000 & 15.291 \\
\hline \multicolumn{5}{|c|}{ Claims on the Non-financial Private Sector/ GDP (PRIVY, cut-off 25/75\%) } \\
\hline-37.592 & 15.155 & 66.564 & 32.986 & 22.887 \\
\hline \multicolumn{5}{|c|}{$\begin{array}{l}{ }^{*} \text { Columns }(1) \text { to }(5) \text { contain percentage contributions of the log differences of the compo- } \\
\text { nents to the log difference of productivity. The percentages are obtained by taking logs } \\
\text { of Equation }(14) \text {, with c being the first year in the sample and b being the final year in } \\
\text { the sample, and computing averages across the countries included in each sample. }\end{array}$} \\
\hline
\end{tabular}


Table 10: Percentage contributions of the productivity components. The role of institutions, 1984-2005

\begin{tabular}{|c|c|c|c|c|c|c|}
\hline $\begin{array}{l}\text { Efficiency } \\
\text { change }\end{array}$ & $\begin{array}{l}\text { Technological } \\
\text { change }\end{array}$ & $\begin{array}{l}\text { Physical } \\
\text { capital } \\
\text { accumulation }\end{array}$ & $\begin{array}{l}\text { Human } \\
\text { capital } \\
\text { accumulation }\end{array}$ & $\begin{array}{l}\text { Financial } \\
\text { development }\end{array}$ & $\begin{array}{l}\text { Institutional } \\
\text { change I }\end{array}$ & $\begin{array}{l}\text { Institutional } \\
\text { change II }\end{array}$ \\
\hline
\end{tabular}

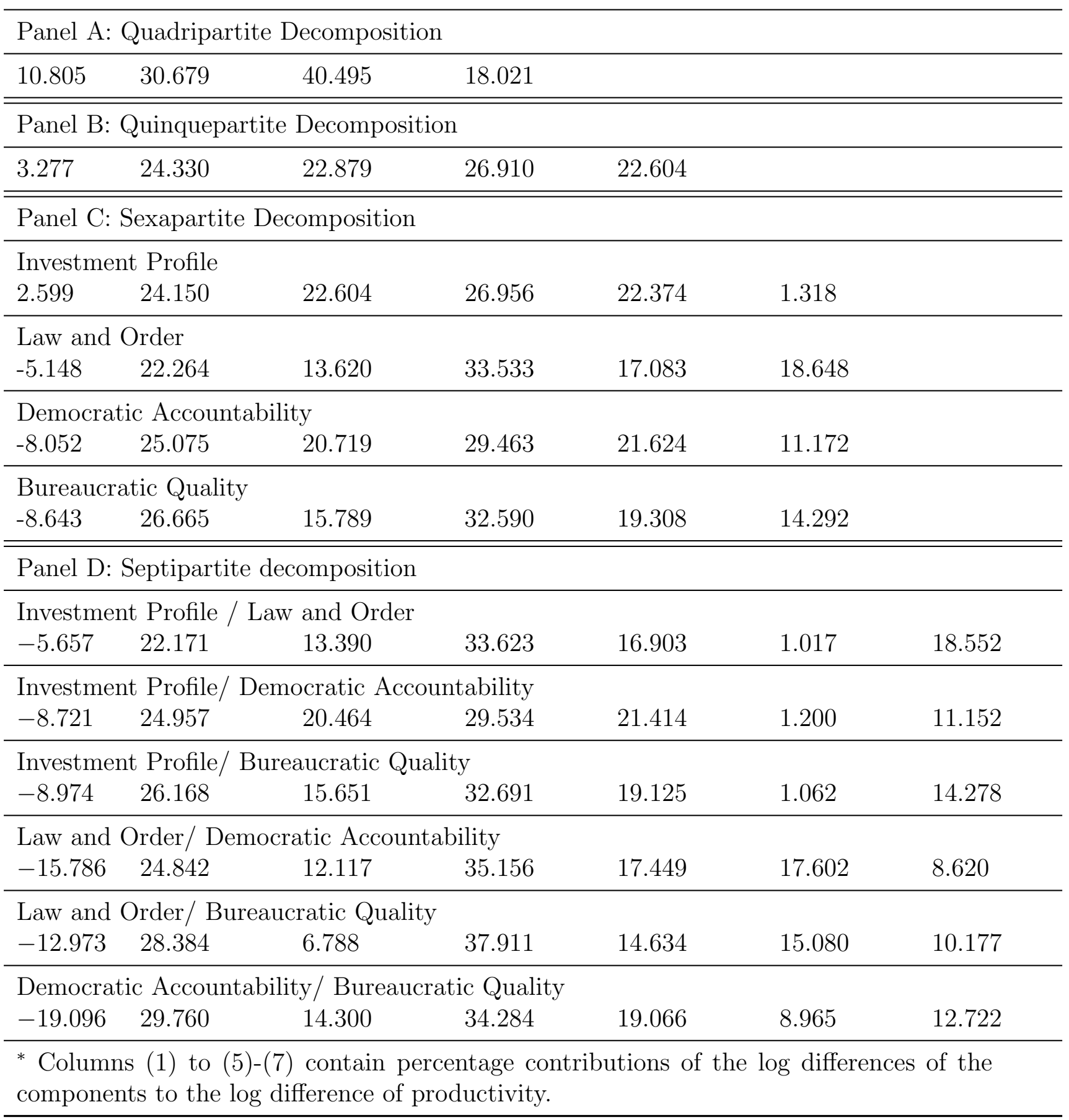


Figure 1: Distributions of financial efficiency augmentation factor, 1965 and 2005

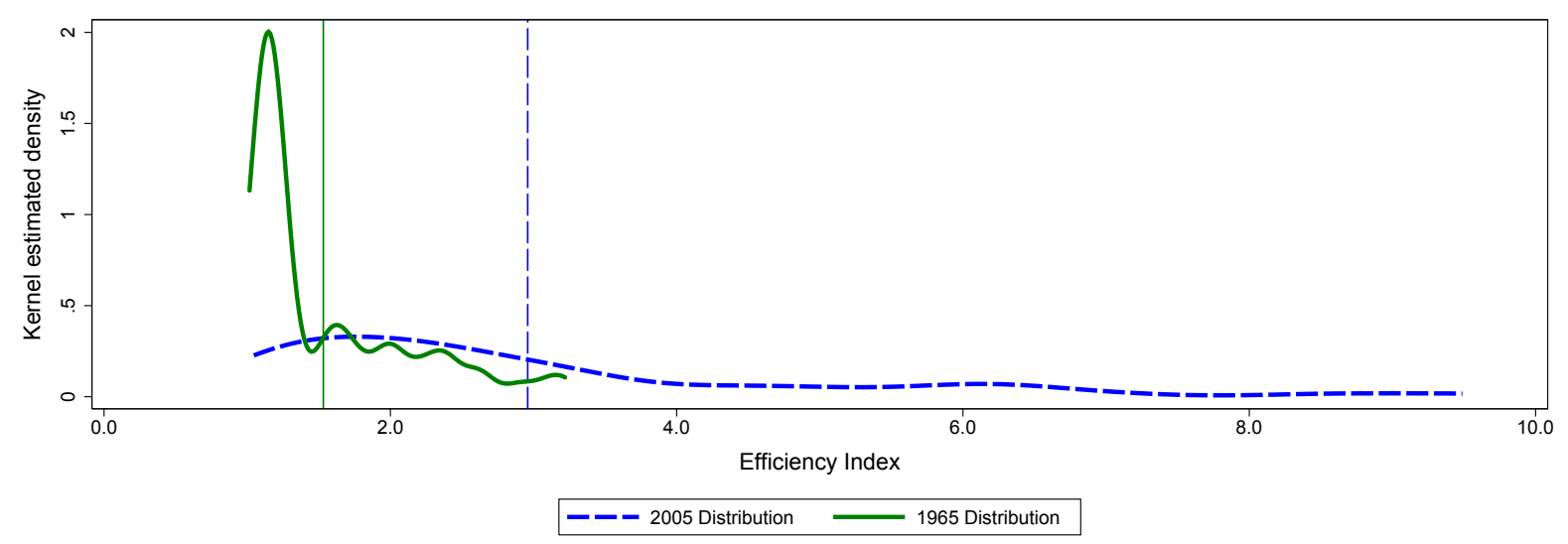

Notes: Estimated 1965 and 2005 distributions of financial efficiency augmentation factor. The solid curve is the estimated 1965 distribution and the solid vertical line represents the 1965 mean value. The dashed curve is the estimated 2005 distribution and the dashed vertical line represents the 2005 mean value. 
Figure 2: Distributions of efficiency index, 1965 and 2005

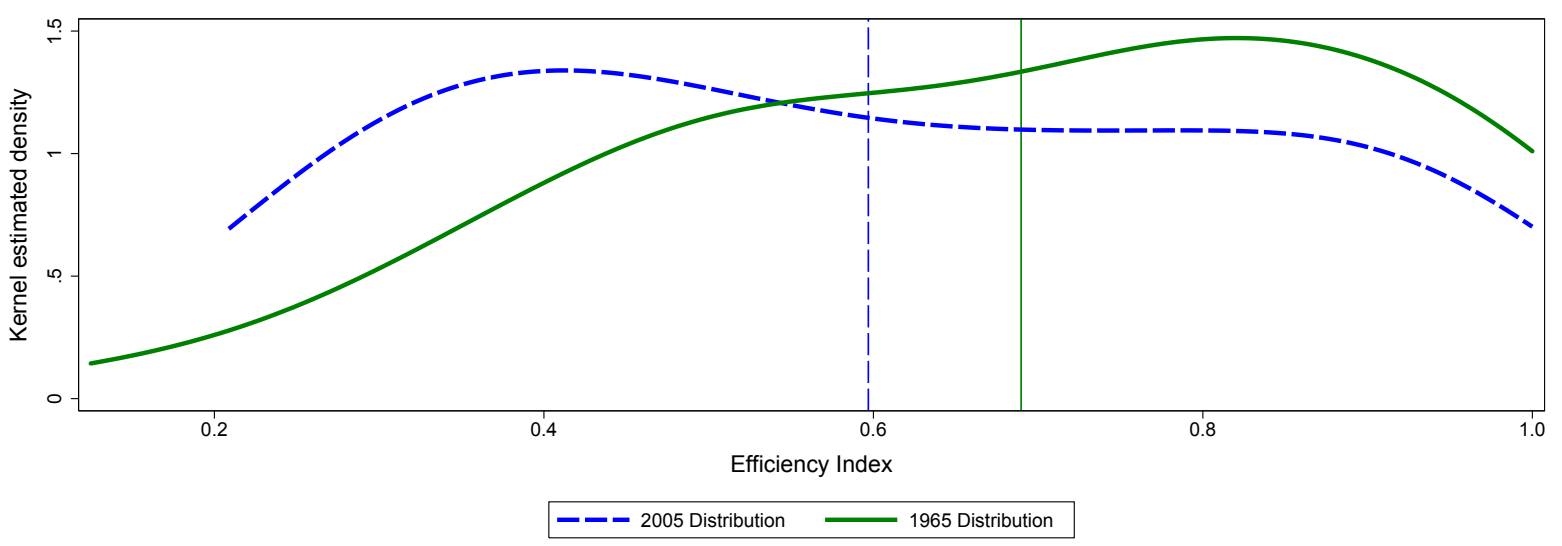

Notes: Estimated 1965 and 2005 distributions of efficiency index. The solid curve is the estimated 1965 distribution and the solid vertical line represents the 1965 mean value. The dashed curve is the estimated 2005 distribution and the dashed vertical line represents the 2005 mean value. 


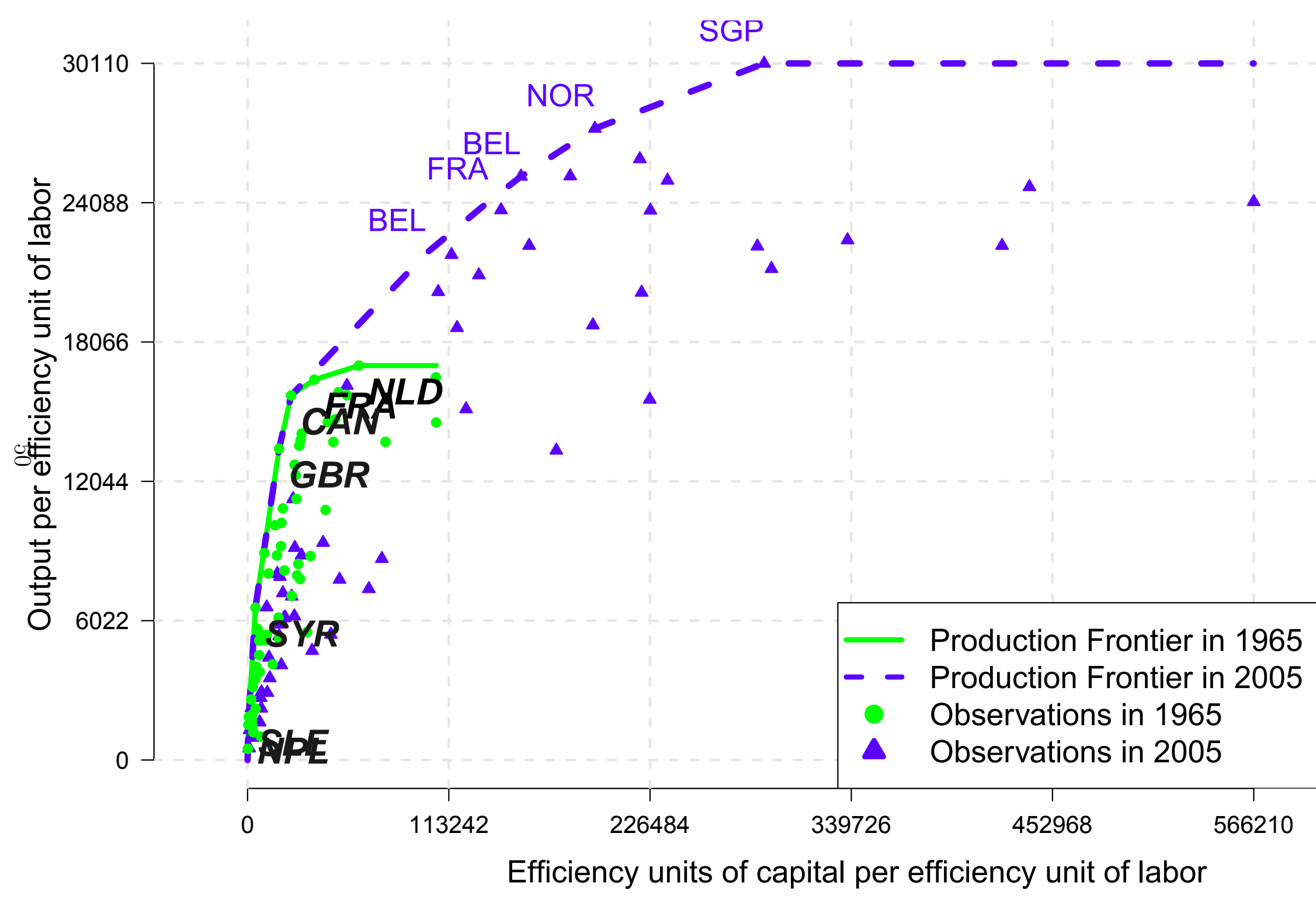

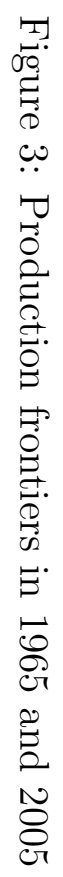


Figure 4: Distributions of output per worker, 1965 and 2005

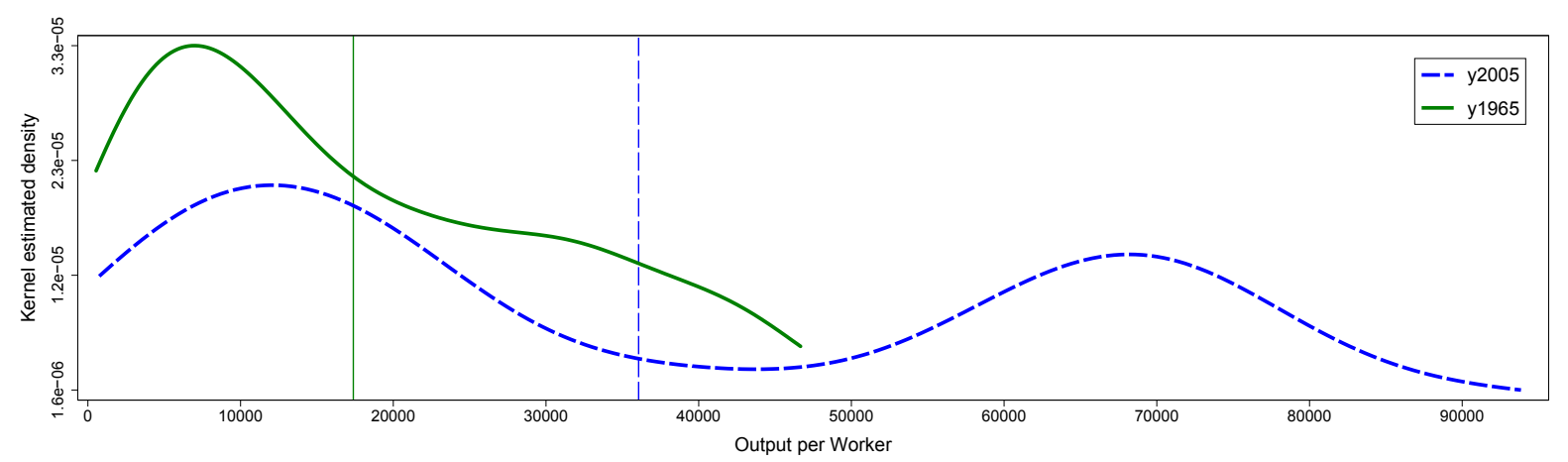

Notes: Estimated 1965 and 2005 distributions of output per worker. The solid curve is the estimated 1965 distribution and the solid vertical line represents the 1965 mean value. The dashed curve is the estimated 2005 distribution and the dashed vertical line represents the 2005 mean value. 
(a) Effect of Efficiency Change

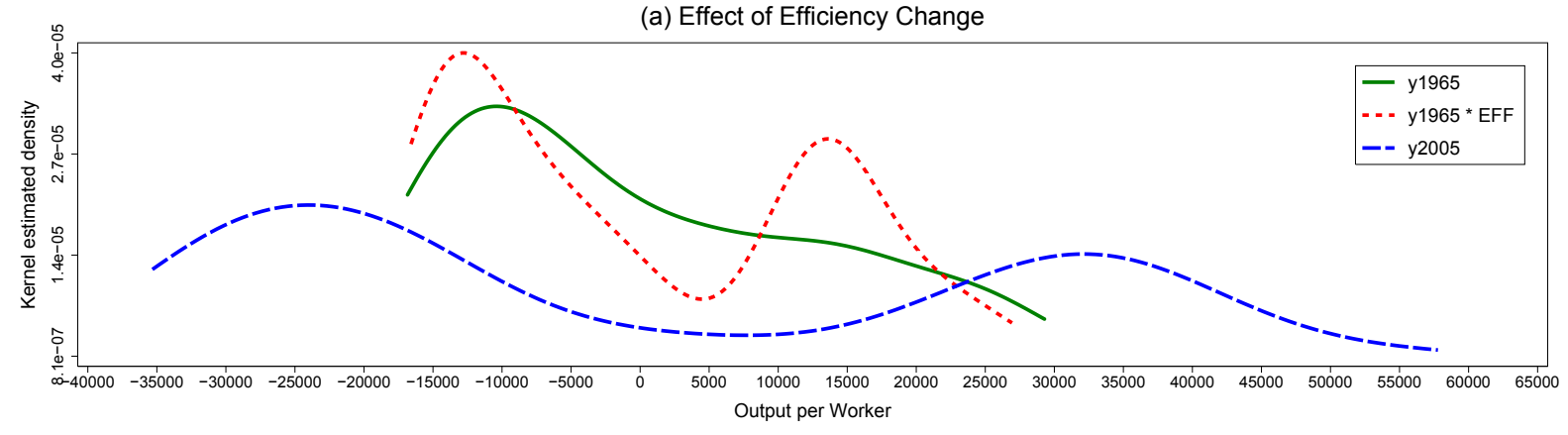

(b) Effect of Capital Deepening

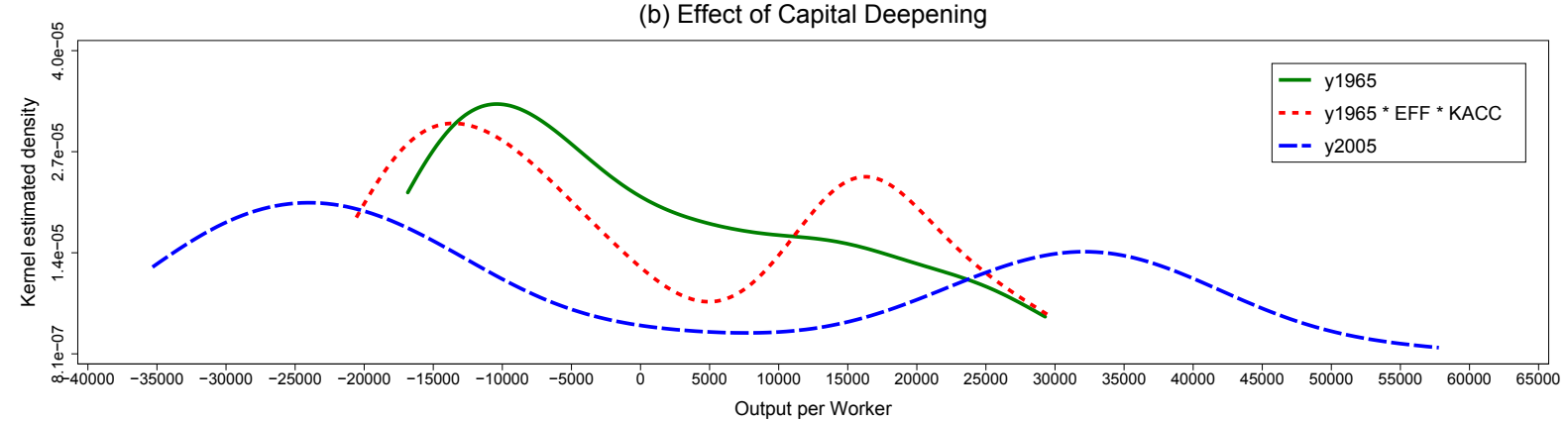

(c) Effect of Human Capital Accumulation

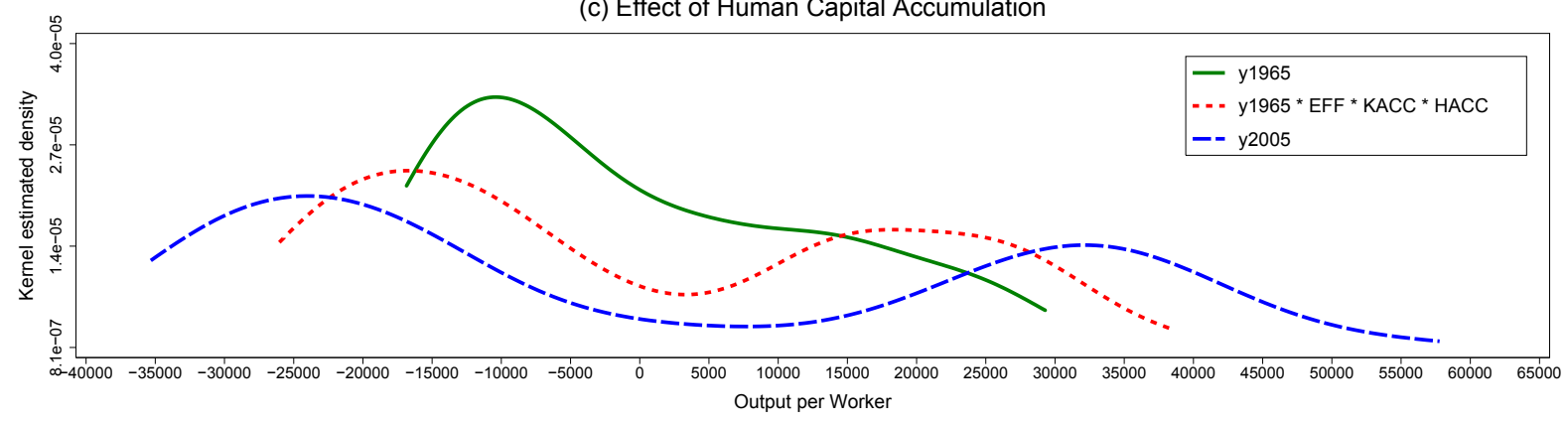

(d) Effect of Financial Development

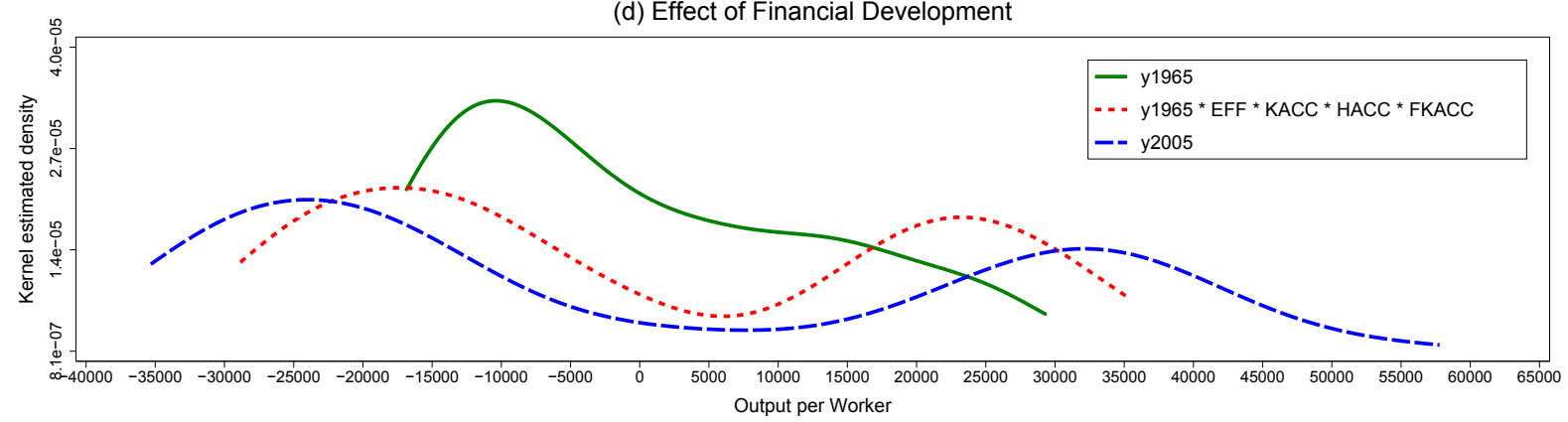

Notes: In each panel, the solid curve is the actual 1965 distribution and the dashed curve is the actual 2005 distribution. The dotted curves in each panel are the counterfactual distributions isolating, sequentially, the effects of efficiency change, capital deepening, human capital accumulation, and financial development on the 1965 distribution.

Figure 5: Counterfactual Distributions of Output per Worker. Sequence of introducing effects of decomposition: EFF, KACC HACC, and FKACC 
(a) Effect of Capital Deepening

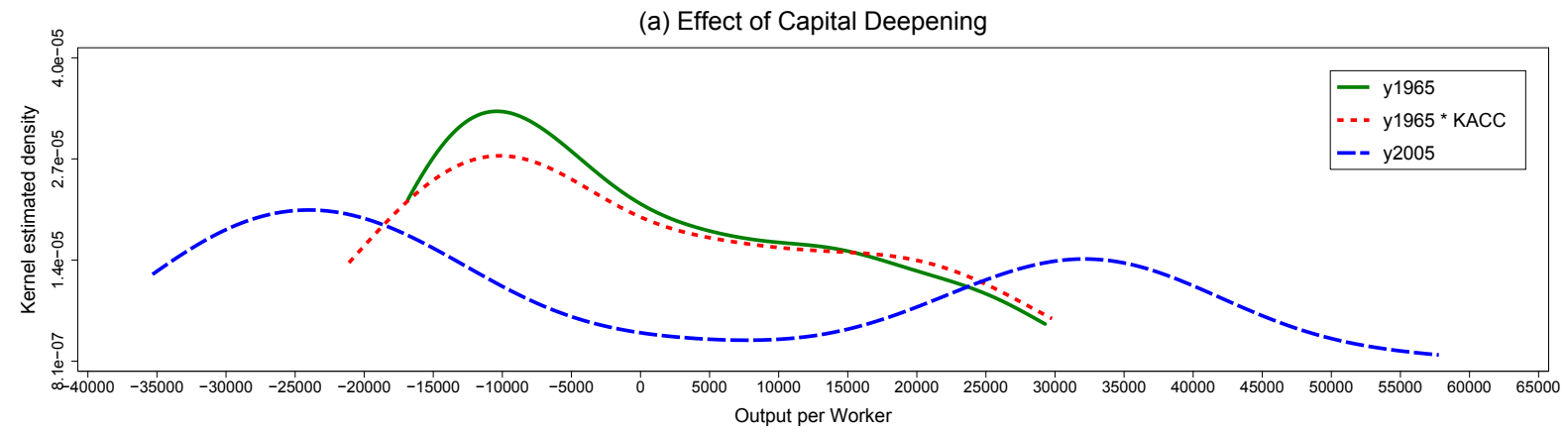

(b) Effect of Technological Change

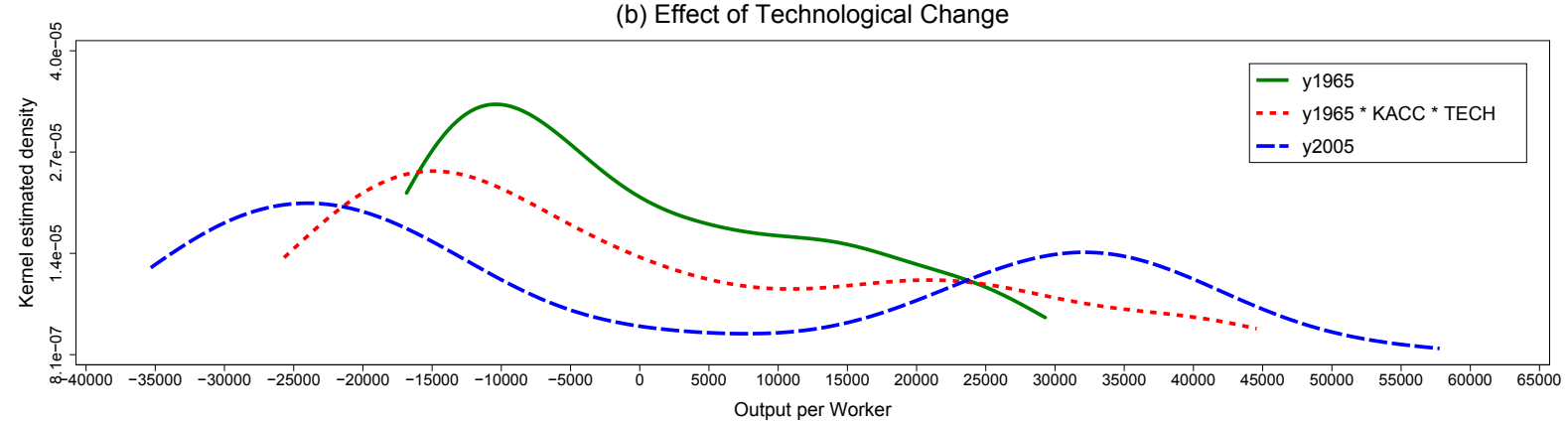

(c) Effect of Efficiency Change

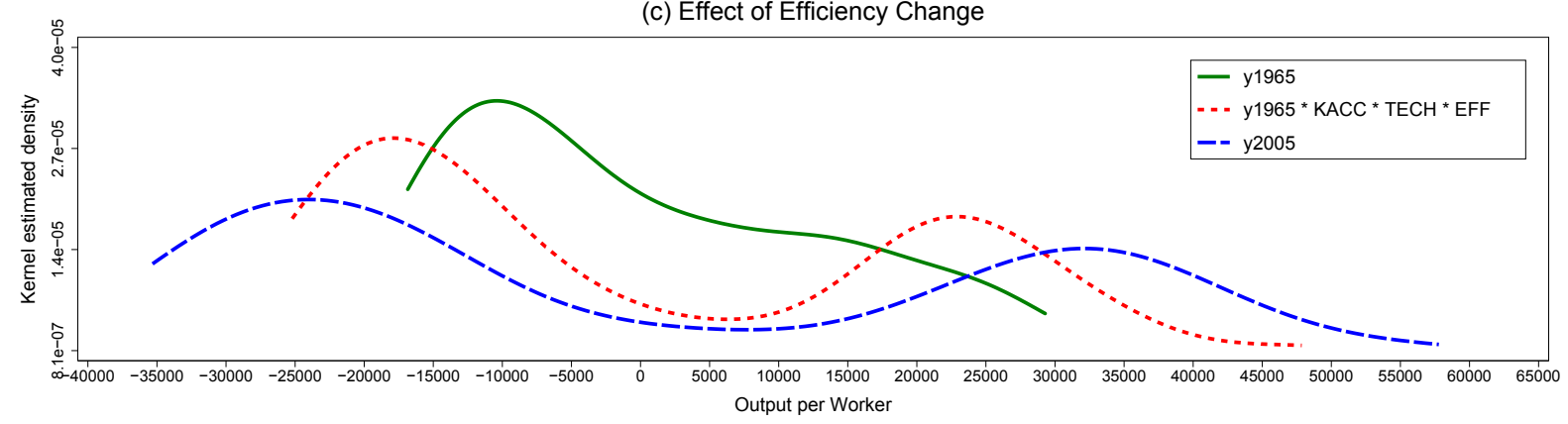

(d) Effect of Human Capital Accumulation

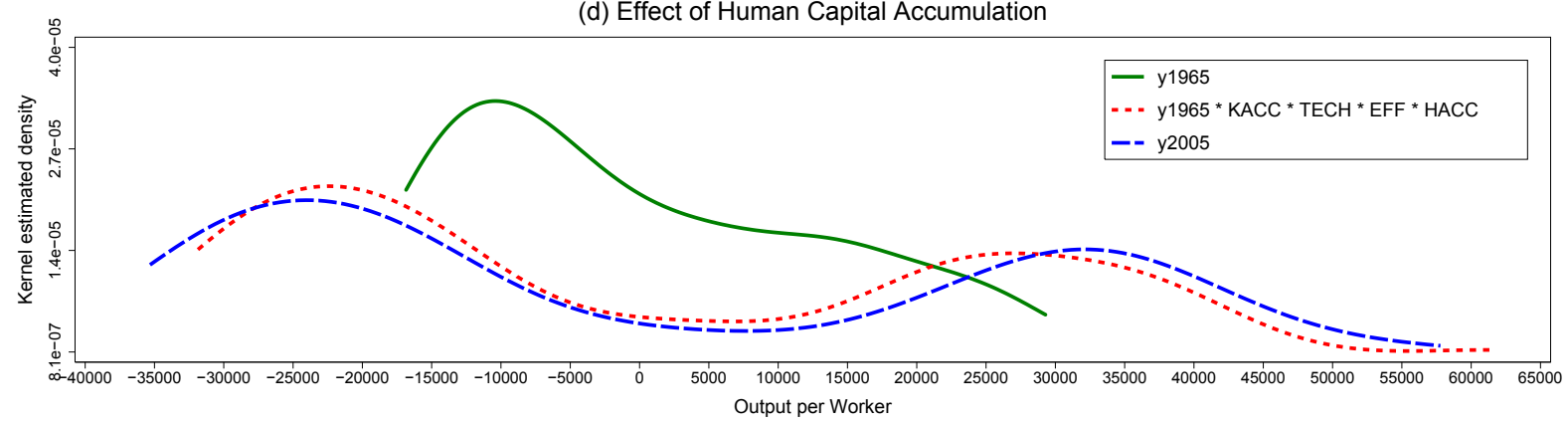

Notes: In each panel, the solid curve is the actual 1965 distribution and the dashed curve is the actual 2005 distribution. The dotted curves in each panel are the counterfactual distributions isolating, sequentially, the effects of capital deepening, technological change, efficiency change, and human capital accumulation on the 1965 distribution.

Figure 6: Counterfactual Distributions of Output per Worker. Sequence of introducing effects of decomposition: KACC, TECH, EFF, and HACC 
(a) Effect of Technological Change

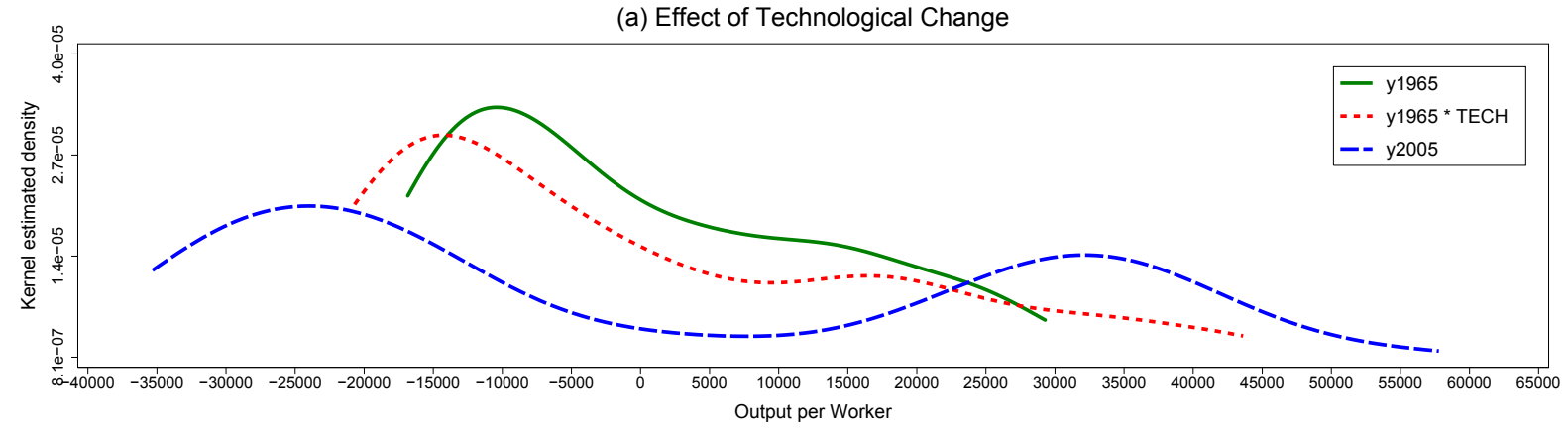

(b) Effect of Financial Development

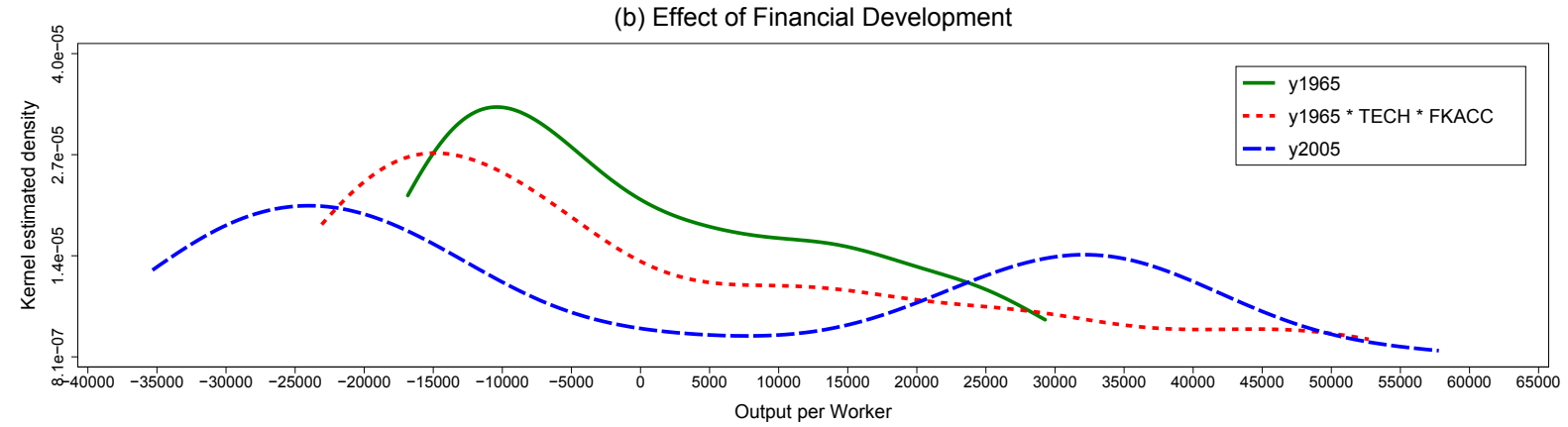

(c) Effect of Capital Deepening

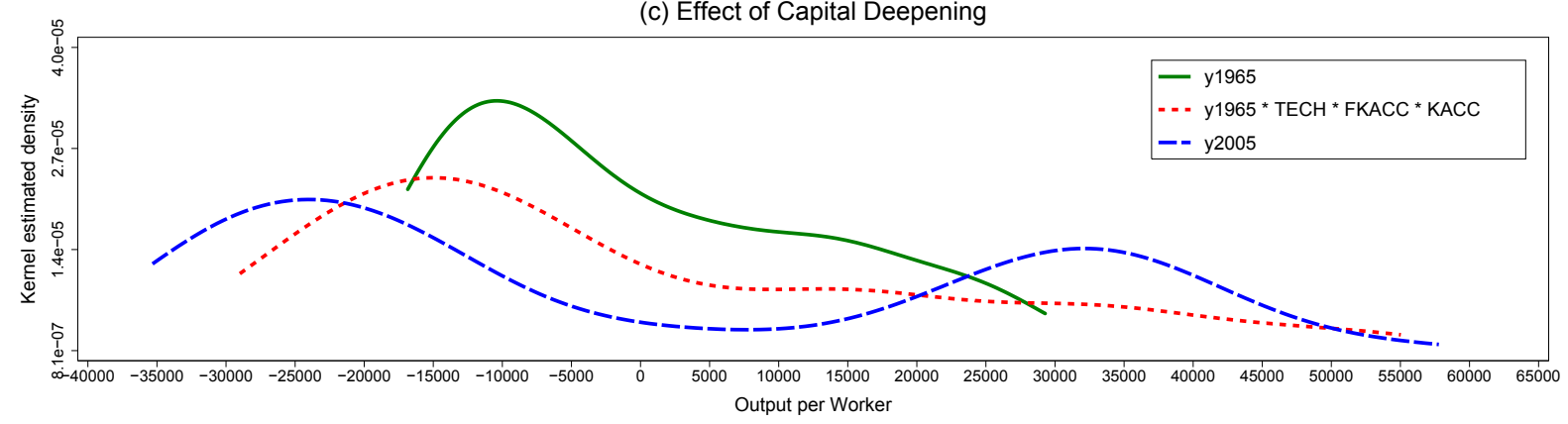

(d) Effect of Efficiency Change

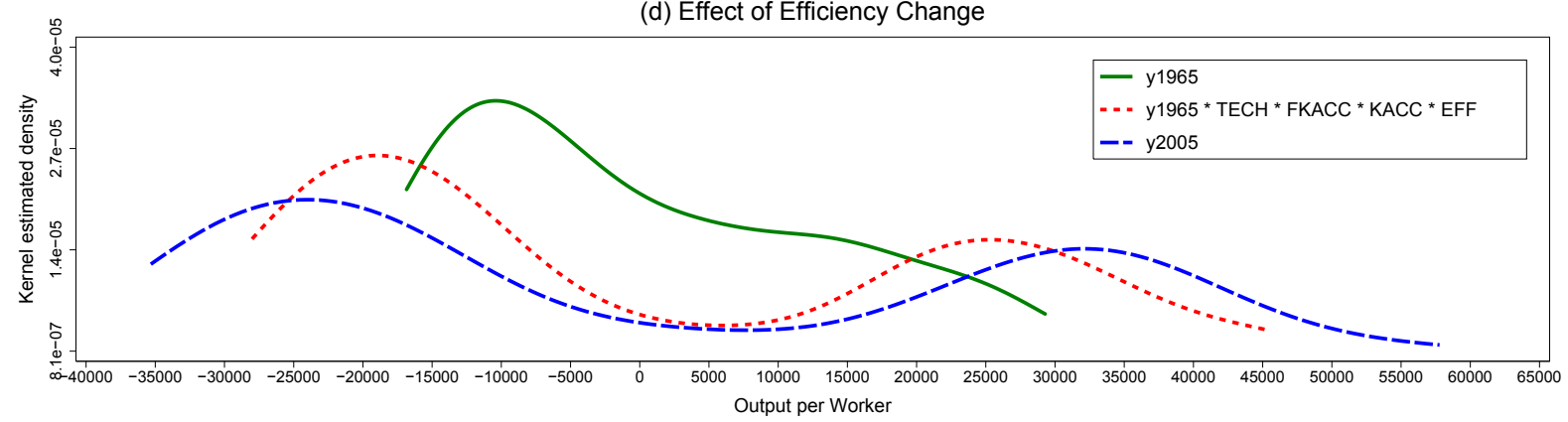

Notes: In each panel, the solid curve is the actual 1965 distribution and the dashed curve is the actual 2005 distribution. The dotted curves in each panel are the counterfactual distributions isolating, sequentially, the effects of technological change, financial development, capital deepening, and efficiency change on the 1965 distribution.

Figure 7: Counterfactual Distributions of Output per Worker. Sequence of introducing effects of decomposition: TECH, FKACC, KACC and EFF 